Review Article

\title{
Recent Advances in Dipeptidyl-Peptidase-4 Inhibition Therapy: Lessons from the Bench and Clinical Trials
}

\author{
Jixin Zhong, ${ }^{1,2}$ Quan Gong, ${ }^{1}$ Aditya Goud, ${ }^{2}$ \\ Srividya Srinivasamaharaj, ${ }^{2}$ and Sanjay Rajagopalan ${ }^{2}$ \\ ${ }^{1}$ Department of Immunology, School of Medicine, Yangtze University, Jingzhou, Hubei 434023, China \\ ${ }^{2}$ Division of Cardiovascular Medicine, Department of Medicine, University of Maryland School of Medicine, Baltimore, \\ MD 21201, USA \\ Correspondence should be addressed to Jixin Zhong; jzhong@medicine.umaryland.edu
}

Received 12 February 2015; Revised 23 April 2015; Accepted 27 April 2015

Academic Editor: Konstantinos Kantartzis

Copyright (C) 2015 Jixin Zhong et al. This is an open access article distributed under the Creative Commons Attribution License, which permits unrestricted use, distribution, and reproduction in any medium, provided the original work is properly cited.

DPP4 inhibitors (DPP4i) are a class of newly developed antidiabetic drugs which preserve incretin hormones and promote postprandial insulin secretion. Although the cardiovascular effect of DPP4 inhibition has been substantially studied, the exact role of DPP4 in cardiovascular disease especially in humans remains elusive. Previous small studies and meta-analyses have suggested a benefit in both surrogate outcomes and cardiovascular events for these agents. However, there was growing evidence in recent years questioning the cardioprotective effect of DPP4i. Further, a signal of heart failure hospitalization in a recent large scale clinical trial SAVOR-TIMI 53 has called into question the safety of these agents and their utility in the treatment of cardiovascular disease. In this review, we will revisit the physiologic function of DPP4 and discuss its role in cardiometabolic disease based on recent experimental and clinical studies.

\section{Introduction}

Dipeptidyl-peptidase-4 (DPP4, also known as CD26) is a membrane glycoprotein that is well known for its role in the catalytic degradation of incretins. DPP4 inhibitors (DPP4i), as a class of antidiabetic medications, have been accepted worldwide, owing to their ease of administration, modest effects on HbAlc, and lack of serious side effects. DPP4 inhibition in experimental models has uniformly demonstrated cardioprotective effects. Indeed early meta-analyses of phase II/III data of DPP4i used in the context of glycemia lowering have shown favorable protective effects of this class in terms of cardiovascular (CV) endpoints, leading to a widespread expectation that these drugs will show a benefit in appropriately designed efficacy trials from a CV standpoint [1-3]. However, recently completed, appropriately designed, phase III trials with the intent of demonstrating benefit from a CV perspective have not shown significant improvement in primary $\mathrm{CV}$ endpoints in patients treated with DPP4i compared to placebo $[4,5]$. In this review, we will summarize the structure and function of DPP4 and its known roles in physiology. We will also review its importance in the pathophysiology of cardiometabolic disorders and provide recent clinical trial evidence that has tested its effects in $\mathrm{CV}$ disease.

\section{Overview of DPP4 Biology}

DPP4 is a transmembrane glycoprotein that forms a homodimer or tetramer on the plasma membrane and cleaves $\mathrm{N}$ terminal dipeptides from proteins with proline or alanine as the penultimate (P1) amino acids. DPP4 is highly conserved among species in terms of amino acid sequence. As shown in Figure 1, DPP4 has a 6-amino-acid N-terminal cytoplasmic domain (AA1-6), a 22-residue transmembrane domain (AA7-29), and a large C-terminal extracellular domain. The extracellular component contains a $\alpha / \beta$-hydrolase domain and an eight-blade $\beta$-propeller domain [6]. This domain is responsible for its dipeptidyl-peptidase activity and its binding to proteins such as adenosine deaminase (ADA) and fibronectin. Residue 294 and residues 340-343 within the 


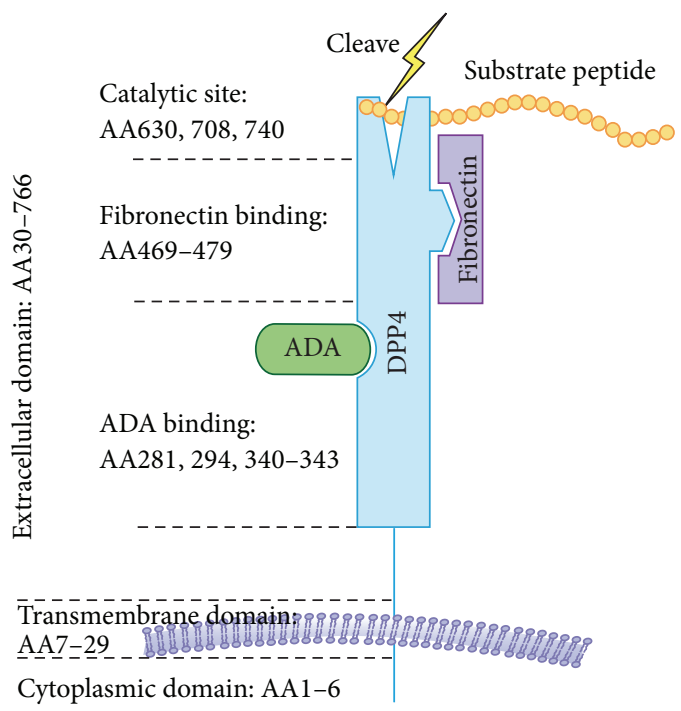

FIGURE 1: DPP4 molecular structure: DPP4 consists of a 6-aminoacid cytoplasmic tail, a 22-amino-acid transmembrane domain, and a large extracellular domain. The extracellular domain is responsible for the dipeptidyl-peptidase activity and binding to its ligands such as ADA and fibronectin. AA, amino acid; ADA, adenosine deaminase.

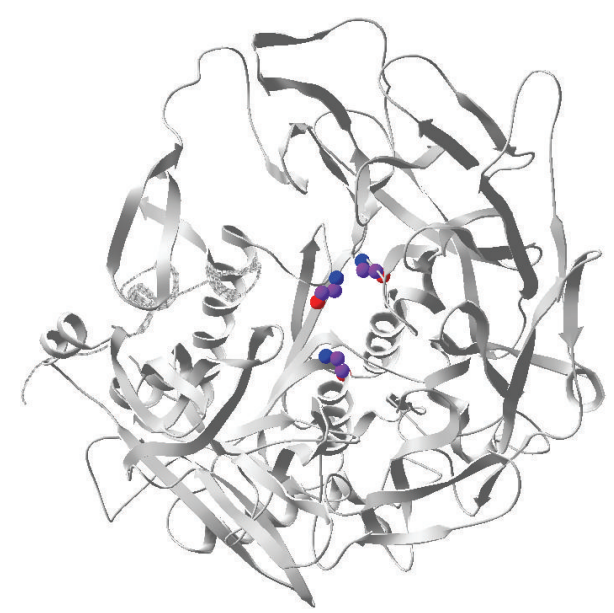

FIGURE 2: Catalytic triad of DPP4: backbone of residues that consist of DPP4 catalytic triad (Ser630, Asp708, and Hsp740) is shown (Purple: C; Blue: N; Red: O).

cysteine-rich segment have been shown to be essential for ADA binding $[7,8]$, while residues 630,708 , and 740 are critical for the catalytic activity of DPP4 (Figure 2 ).

2.1. DPP4 Expression and Regulation. DPP4 is widely expressed in many organs, such as the kidney, spleen, lungs, pancreas, and prostate [9]. It is expressed at high levels on endothelial cells, differentiated epithelial cells, and some immune cells such as $\mathrm{T}$ cells, dendritic cells, and macrophages. DPP4 is also present in plasma as a soluble form, which either comes from a shedding process driven by proteinases or is released into circulation by means of vesicles such as exosomes, ectosomes, and apoptotic bodies.
Altered expression of soluble DPP4 is commonly seen in many disorders such as solid tumors, autoimmune diseases, hepatitis C, type 2 diabetes (T2DM), and obesity [10-12].

The regulation of DPP4 expression is not fully understood. Studies have suggested that STAT1 $\alpha$ [13] and hepatocyte nuclear factor-1 (HNF-1) [14] mediate the transcription of DPP4. In an in vitro experiment, cotransfection of HNF- $1 \alpha$ and $1 \beta$ enhanced reporter gene expression under the control of DPP4 promoter [14]. DPP4 promoter region also contains a GAS (interferon gamma-activated sequence) motif, which is a binding site of STAT $1 \alpha$. Indeed, STAT $1 \alpha$ activation by administration of both interferons and retinoic acid leads to the binding of STAT $1 \alpha$ to the GAS motif and a subsequent DPP4 transcription [13]. In addition to transcriptional regulation, DPP4 is also regulated at posttranscriptional level. IL12 enhances the translation, but not transcription, of DPP4 in activated lymphocytes [15]. Many other cytokines are also involved in the regulation of DPP4 expression. IL- $1 \alpha$ has been shown to be responsible for the upregulation of DPP4 in fibroblast, epithelial cells, and stromal cells $[16,17]$. Polarization to $\mathrm{T}_{\mathrm{H}} 17$ by TGF $\beta$, IL-23, IL-6, IL-1 $\beta$, and IL-21 also showed an increased expression of DPP4 [18].

2.2. Dipeptidyl-Peptidase Activity of DPP4. Incretin peptides such as gastric inhibitory polypeptide (GIP) and glucagonlike peptide (GLP-1) are responsible for the modulation of postprandial blood glucose by promoting insulin secretion from pancreatic $\beta$ cells and via glucagonostatic effects. GLP-1 and GIP are rapidly inactivated by DPP4, leading to a short half-life (minutes for both GLP-1 and GIP). Mice lacking DPP4 $\left(D p p 4^{-/-}\right)$are protected from the development of dietinduced obesity and demonstrate improved postprandial glucose control $[19,20]$. Pair-feeding and indirect calorimetry studies have shown that reduced food intake and increased energy expenditure accounted for the resistance to dietinduced obesity in $D p p 4^{-/-}$mice. $D p p 4^{-/-}$mice also demonstrate improved insulin sensitivity, reduced pancreatic islet hypertrophy, and protection against streptozotocin-induced $\beta$ cell loss and hyperglycemia [19]. Pharmacological inhibition of DPP4 enzymatic activity improved glucose tolerance in wild-type but not in Dpp4 $4^{-/-}$mice. DPP4 inhibition also improves glycemic control in $\mathrm{Glplr}^{-/-}$mice, suggesting additional mechanisms for DPP4 inhibition-mediated antihyperglycemic effect [20].

In addition to incretin peptides, DPP4 also cleaves a number of other proteins. The physiologic targets include GLP1, GLP2, brain natriuretic peptide (BNP), peptide YY, stromal-cell-derived factor-1 (SDF-1), erythropoietin, granulocyte colony-stimulating factor (G-CSF), and substance P (3-11). Pharmacologic targets (evidence provided by in vitro cell culture and/or incubation experiments with substrate and DPP4) include gastrin-releasing peptide, growth-hormonereleasing factor, macrophage derived chemokine, eotaxin, IFN- $\gamma$-induced protein-10, granulocyte-macrophage colonystimulating factor, erythropoietin, IL-3, neuropeptide Y, Btype natriuretic peptide, and peptide YY. The catalytic activity of DPP 4 has been extensively reviewed elsewhere and will not be discussed here in detail [21-23]. 
2.3. Inflammation Mediated by DPP4-ADA Interaction. In addition to its peptidase activity, DPP4 also possesses noncatalytic function via interactions with a range of ligands including ADA, caveolin-1, fibronectin, coronavirus spike protein, collagen, glypican-3, insulin-like growth factor 2 receptor, fibroblast activation protein, and CXCR4. By interacting with these ligands, DPP4 plays a role in a variety of processes such as enhancing $\mathrm{T}$ cell activation and functional modulation of antigen presenting cells (APCs).

The costimulatory function of DPP4 was first described in early 1990s [24]. Ligation of DPP4 by ADA or anti-DPP4 antibodies recognizing ADA binding epitope enhanced T cell activation, proliferation, and cytokine production. Crosslinking by anti-DPP4 antibody induced tyrosine phosphorylation of a subset of proteins [25]. These phosphorylated molecules include signaling molecules downstream TCR/CD3, such as p56 ${ }^{\text {1ck }}, \mathrm{p} 59^{\text {fyn }}$, ZAP-70, MAP kinase, c$\mathrm{Cbl}$, and phospholipase $\mathrm{C} \gamma$ [26]. Since DPP4 has a very short intracellular domain (6 AAs), it relies on other proteins to transduce signaling in cells. Torimoto et al. reported that activation of DPP4 by its ligand leads to coaggregation of CD45RO into lipid rafts, suggesting that DPP4 may transduce costimulation via CD45 [27]. This result is consistent with the observation that DPP4 high $\mathrm{T}$ cells are restricted to the $\mathrm{CD}_{45 \mathrm{RO}^{+}}$cells $[28]$ and $\mathrm{CD}^{+} \mathrm{T}$ cells lacking DPP4 cannot be triggered to elicit a memory $\mathrm{T}$ cell response [29]. As we will discuss below, DPP4-ADA interaction may also promote $\mathrm{T}$ cell activation by degrading adenosine, an immunosuppressive metabolite. In addition, interaction of DPP4 with caveolin-1 may form a complex consisting of DOO4, CARMA1, Bcl10, MALT1, and I $\kappa$ B kinase in the lipid rafts on $\mathrm{T}$ cell membrane, leading to the activation of NF- $\kappa \mathrm{B}$ [30].

2.4. DPP4 as an Entry Protein for Coronavirus. Middle East Respiratory Syndrome (MERS), a viral respiratory illness, was first reported in Saudi Arabia in 2012. It was caused by the infection of a coronavirus, MERS-CoV. The mortality from MERS is approximately $30 \%$ [31]. DPP4 was subsequently identified as a functional receptor for the entry of MERS-CoV in human and bat cells [32]. The engagement of the MERSCoV spike protein S with DPP4 mediates viral attachment and internalization. The residues involved in the DPP4 virus binding are identical to the ADA binding domain indicating a potential competition for DPP4 binding [33]. Human, macaque, horse, and rabbit DPP4 have been suggested to be able to bind MERS-CoV and therefore are susceptible to infection. However, small animals such as mice are more divergent with respect to the DPP4 virus binding region and are not susceptible to MERS-CoV infection [34]. DPP4 has been previously reported as a cofactor for the entry of HIV in the $\mathrm{CD} 4^{+} \mathrm{T}$ cells [35]. However, subsequent studies identified CCR5 and CXCR4 as the major coreceptors for HIV [36-39]. The coexpression of DPP4 and CCR5 may partially explain the association between DPP4 expression and HIV infection [40].

2.5. DPP4/Caveolin-1-Mediated Immune Activation. Ohnuma et al. reported that DPP4 interacts with caveolin-1 present on APCs and initiates a signaling cascade in antigen loaded APCs, resulting in their activation [41, 42]. Upon binding to DPP4, caveolin-1 is phosphorylated, resulting in the phosphorylation of IRAK-1 and its disassociation with Tollip. Phosphorylated IRAK-1 then activates NF-kappa B $(\mathrm{NF} \kappa \mathrm{B})[43,44]$, which in turn upregulates CD86 [42]. The interaction between DPP4 and caveolin-1 has been reported to be involved in the pathogenesis of arthritis [45].

DPP4 has also been reported to bind multiple components of extracellular matrix such as collagen, fibronectin, and the HIV-1 Tat protein [46, 47]. Interactions with these matrix components may play a role in sequestration of DPP4 and allow additional functions such as matrix remodeling, metastasis, and chemotaxis.

\section{DPP4 and Diabetes}

3.1. DPP4 Expression in Obesity and Diabetes. Circulating DPP4 activity has been reported to be increased in patients with obesity and T2DM, positively correlating with HbAlc levels, degree of obesity, and measures of insulin resistance and inflammation [48, 49]. Lugari et al. reported that the increase of circulating DPP4 activity in diabetic patients results in a reduction of plasma GLP-1 (fasting and in response to meals) [50]. In addition to circulating DPP4 activity, the expression of DPP4 on T cells and dendritic cells is also increased in patients with T2DM [51]. However, there are also reports suggesting a decrease of circulating DPP4 activity in patients with T2DM [52]. This potential contradiction may relate to the fact that, in these studies, many patients were on concomitant medications. Several widely used antidiabetic medications including thiazolidinedione, pioglitazone, and metformin have been reported to reduce circulating DPP4 [53-55] and DPP4 expression on T cells [51]. This may reflect improvement in glycemic control and other measures of inflammation resulting in the reciprocal decrease in DPP4 expression. An enhanced expression of hepatic DPP4 has also been reported in nonalcoholic fatty liver disease and its expression may adversely affect glucose metabolism in this condition [56]. In vitro stimulation of HepG2 cells with high glucose increased the expression of DPP4, whereas insulin, fatty acids, and cholesterol did not [56].

3.2. Catalytic Function and Diabetes. Incretin hormones, GLP-1 and GIP, both potentiate insulin secretion from pancreatic $\beta$ cells through G-protein-coupled receptors $[57,58]$. As mentioned above, both GLP-1 and GIP can be inactivated by DPP4, resulting in a short half-life, less than $2 \mathrm{~min}$ for GLP-1 and less than $2 \mathrm{~min}$ in rodents or $7 \mathrm{~min}$ in human for GIP [59-61]. In patients with T2DM, incretin response is attenuated with an increase in plasma DPP4 enzymatic activity as well as heightened tissue DPP4 expression and release in tissues such as visceral adipose. The increase in DPP4 levels and expression correlates with the degree of glycemia/insulin resistance, suggesting that DPP4 mediated incretin degradation is involved in the pathogenesis of T2DM. 
There are several DPP4i approved or being approved by FDA or EU as antidiabetic drugs, such as sitagliptin, saxagliptin, linagliptin, vildagliptin, and alogliptin. Most clinical trials with DPP4i demonstrate approximately a 0.6$0.8 \%$ lowering of $\mathrm{HbA1C}$ in patients with a baseline level around $8 \%$ [62]. The placebo-subtracted $\mathrm{HbAlc}$ reductions with DPP4i are generally greater in patients with higher baseline HbAlc. In general, most studies also corroborate improvements in homeostasis model assessment beta cell function index (HOMA- $\beta$ ) and fasting proinsulin: insulin ratio, suggesting improvement in $\beta$ cell function [63]. The incidence of side effects and hypoglycemia are very low with these agents $[63,64]$. In clinical trials, the most common reported side effects of DPP4i include nasopharyngitis, upper respiratory tract infection, urinary tract infection, and headache [65]. Saxagliptin [66] and linagliptin [67] were recently approved by FDA. In contrast to other members of the class, linagliptin has a primarily nonrenal route of excretion and therefore would not need dose adjustment, regardless of renal impairment [68]. In addition to those approved drugs, more DPP4i including dutogliptin and gemigliptin are under development and are awaiting FDA approval.

3.3. Noncatalytic Function and Diabetes. Inflammation plays a key pathogenic role in the development of insulin resistance and T2DM [69]. Innate immune mechanisms typified by macrophage infiltration and activation are widely believed to represent major mediators of adipose inflammation. However, recent findings suggest that $\mathrm{T}$ cells may also play an important role in this process. Activated $\mathrm{CD}^{+}$effector $\mathrm{T}$ cells have been shown to promote adipose inflammation by enhancing macrophage recruitment and activation, while $\mathrm{CD}^{+} \mathrm{T}$ cells especially $\mathrm{T}_{\mathrm{H}} 2$ and regulatory $\mathrm{T}$ cells which are the $\mathrm{T}$ cell subpopulations expressing lowest levels of DPP4 [18] were suggested to be protective in the development of adipose inflammation and insulin resistance [70]. As mentioned above, DPP4 provides T cell costimulatory signals. Therefore, DPP4 might play a role in the development of adipose inflammation and insulin resistance although there is a lack of direct evidence.

In addition to mediating costimulatory signaling, interaction between DPP4 and adenosine deaminase (ADA) may also facilitate $\mathrm{T}$ cell activation by providing a suitable microenvironment for $\mathrm{T}$ cell proliferation. Inherited mutations in ADA activity cause severe combined immunodeficiency (SCID) in both human and mice [71-73]. Extracellular ATP or ADP is initially converted to AMP by CD39 and CD73 to produce adenosine [74]. Adenosine is then processed by ADA and converted to inosine [75]. By anchoring ADA onto the cell surface, DPP4 modulates pericellular adenosine levels and thus regulates $\mathrm{T}$ cell activation (Figure 3 ). Absence of ADA activity results in the accumulation of adenosine, which dose-dependently inhibits $\mathrm{T}$ cell proliferation. Jurkat cells expressing DPP4 mutant devoid of ADA binding activity are sensitive to adenosine-mediated inhibition of $\mathrm{T}$ cell proliferation [7]. In contrast, cells expressing ADA and DPP4 on the surface are much more resistant to the inhibitory effect of adenosine $[7,76,77]$. We have recently demonstrated that

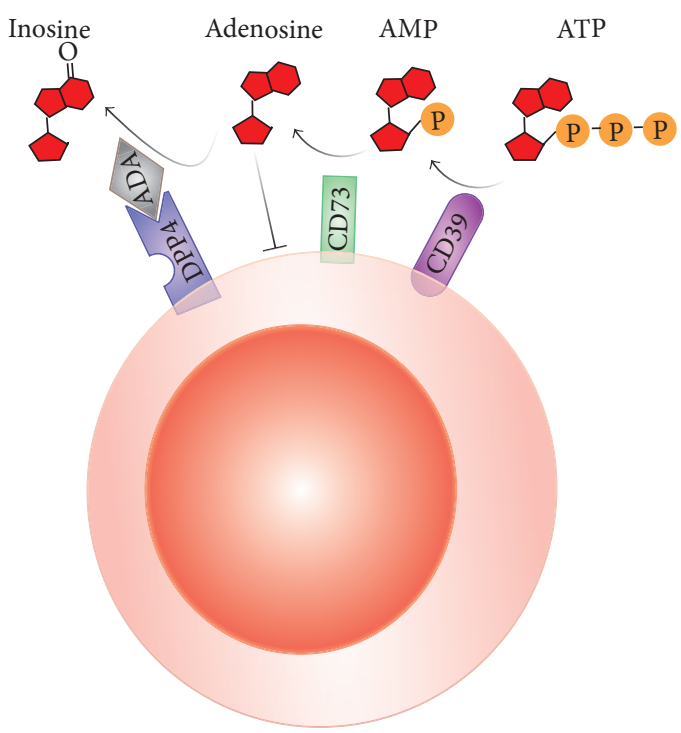

FIGURE 3: Role of ADA-DPP4 interaction in adenosine clearance: by binding to DPP4 on the cell surface, ADA reduces pericellular levels of cytotoxic metabolite adenosine by converting it into a nontoxic product inosine.

DPP4 expressed on adipose tissue macrophages is involved in inflammation and insulin resistance by interacting with ADA [77]. Expression of DPP4 on adipose tissue macrophages was higher than that in circulation and was increased in obese and insulin resistant patients. Furthermore, DPP4 level on adipose tissue macrophage positively correlated with degree of insulin resistance. DPP4 on antigen presenting cells, including macrophages and dendritic cells, facilitated $\mathrm{T}$ cell proliferation and activation through its noncatalytic activity as catalytic inhibition of DPP4 or addition of exogenous sDPP4 did not affect their capability to stimulate $\mathrm{T}$ cells. Antigen presenting cell-expressing DPP4 was able to bind ADA and promote T cell activation via removal of suppressive effect of adenosine [77]. These results suggest that DPP4 on antigen presenting cells is capable of promoting inflammation and insulin resistance through its noncatalytic function. Interestingly, murine and rat DPP4 do not bind ADA [78]. Although adenovirus delivery of human DPP4 into mouse has been developed to study MERS-CoV infection [79], in vivo rodent models for the investigation of DPP4-ADA interaction of relevance to human diabetes are currently unavailable.

\section{Role of DPP4 and Incretin System in Cardiovascular System}

4.1. Incretins in Vascular Biology. The signaling of GLP-1 is mediated through GLP-1R. GLP-1R was originally identified in pancreatic $\beta$ cells but is widely expressed in many tissues and organs including the lungs, kidney, central/peripheral nervous system, and the cardiovascular system [57]. The receptor for GLP-1 (GLP-1R) is expressed in cardiovascular cells including endothelial cells, cardiomyocytes, and 
coronary smooth muscle cells [80]. GLP-1R belongs to the family of G-protein-coupled receptors. The engagement of GLP-1R leads to the activation of adenylate cyclase through stimulatory Gs subunit and subsequent accumulation of cAMP in classically responsive cells such as pancreatic $\beta$ cells $[81,82]$. For example, in $\beta$ cell, the activation of GLP-1 activates PKA, which subsequently reduces Foxol and results in an increase of Foxa2. Foxa2 then increases PDX-1, a transcription factor for insulin [83]. Via a cAMP-dependent pathway, GLP-1R signaling may also induce the activation of $\mathrm{PI} 3 \mathrm{~K}$ which further increases the expression of Bcl-2 and Bcl$\mathrm{xL}$, two antiapoptotic proteins [84].

There is evidence indicating that GLP-1 signaling is involved in the cardioprotective effects of DPP4 inhibition. For example, it has been shown that acute infusion of GLP1 improves endothelial dysfunction in patients with T2DM $[85,86]$. Exendin-4, a GLP-1R agonist, was also shown to stimulate proliferation of human coronary artery endothelial cells through eNOS-, PKA-, and PI3K/Akt-dependent pathways [87]. Both DPP4i and GLP-1 can increase endothelial progenitor cells (EPCs), suggesting a role of a GLP-1dependent pathway in the development of EPCs $[88,89]$. Moreover, GLP-1 can increase left ventricular developed pressure and coronary flow in isolated mouse hearts [90]. Further studies have confirmed that the protective effect of GLP-1 on endothelial cells is mediated through increasing nitric oxide (NO) production [91]. Activation of GLP-1R appears to have cardioprotective effect in humans and various animal models and its effects on contractility, blood pressure, and cardiac output appear to be independent of its antidiabetic effect [92]. Both enzymatic inhibition and genetic deletion of DPP4 reduced heart infarct size in ischemic models by preserving GLP-1 $[1,93]$. In vitro treatment of cardiomyocyte with GLP$1 \mathrm{R}$ agonist reduced caspase- 3 cleavage and apoptosis induced by various stimulations such as TNF $\alpha$, hypoxia, and lipidemia [94-96]. Zhao et al. reported that GLP-1 increased p38 MAPK activity, nitric oxide (NO) production, and GLUT1 expression in isolated hearts and thus increased myocardial glucose uptake during aerobic perfusion [97]. Consistent with this, Nikolaidis et al. reported that $48 \mathrm{~h}$ continuous GLP-1 infusion $(1.5 \mathrm{pmol} / \mathrm{kg} / \mathrm{min})$ in a conscious dog increased myocardial glucose uptake and left ventricular hemodynamics [98]. Pretreatment of p38 MAPK inhibitors could inhibit this effect [99]. However, there have been conflicting observations of GLP-1 effect on myocardial contractility. GLP-1 was reported to be able to decrease contractility in primary cultured adult rat cardiomyocytes, despite increasing cAMP levels [100]. The addition of $0.5 \mathrm{nM}$ GLP-1 to the perfusate reduced left ventricular developed pressure [97], while $0.3 \mathrm{nM}$ GLP-1 increased left ventricular developed pressure by $20 \%$ during Langendorff aerobic perfusion of isolated mouse hearts [90]. Studies on $\mathrm{Glplr}^{-/-}$mice suggest that the absence of GLP-1R increases baseline left ventricular developed pressure [90]. Although acute administration of GLP-1 or exendin- 4 increases heart rate and blood pressure at least in rodent models [101-103], chronic treatment of exendin-4 (20 nmol/kg twice daily) for $12 \mathrm{wk}$ displayed a marked reduction in systolic blood pressure in both $\mathrm{db} / \mathrm{db}$ mice and angiotensin-II-infused C57BL/6 mice [104]. In line with these animal studies, majority of clinical trials have also reported a reduction of blood pressure after chronic treatment of GLP-1R agonist [105-107]. It has also been suggested that GLP-1 exerts protective effect on atherosclerosis. Continuous infusion of exendin- 4 for 4 weeks reduced neointimal formation [108], foam cell formation [109], and atherosclerotic lesion size $[109,110]$. Some of these effects may relate to favorable effects of GLP-1 on lipoprotein metabolism. Infusion of GLP-1 (20 pmol $/ \mathrm{kg} / \mathrm{min})$ via jugular vein reduces triacylglycerol absorption and intestinal ApoB- 48 production in rats [111]. Hsieh et al. reported that exendin-4 $(24 \mathrm{nmol} / \mathrm{kg}$, i.p.) and sitagliptin $(10 \mathrm{mg} / \mathrm{kg}$, gavage) reduced postprandial triacylglycerol and ApoB-48 after oral fat load in C57BL/6 mice, whereas $\mathrm{Glp}_{1} \mathrm{r}^{--}$mice had an increased plasma level of triacylglycerol after oral fat load [112]. Human studies have shown that acute GLP-1 infusion $(1.2 \mathrm{pmol} / \mathrm{kg} / \mathrm{min})$ suppressed postprandial plasma triacylglycerol and free fatty acid levels [113]. Short-term treatment of GLP-1 ( $25 \mathrm{nmol} \mathrm{sc}$ injection before meals for 5 days) decreased plasma VLDLtriacylglycerol by $38 \%$ [114]. The lipid lowering effects of GLP1 and DPP4 have been reviewed in detail previously [115].

4.2. DPP4 in Vascular Biology. DPP4 is expressed in endothelial cells and may mediate cardiovascular effects in both GLP-1-dependent or -independent manner, although the functional significance of these effects has not been fully elucidated. By incubating isolated aorta rings with DPP4 enzymatic inhibitor, we provided direct evidence showing that DPP4 inhibition relaxes aorta through a GLP-1independent pathway. Alogliptin, a DPP4 inhibitor, but not GLP-1, induces eNOS and Akt phosphorylation $\left(\mathrm{Ser}^{1177}\right.$ and $\mathrm{Ser}^{473}$, resp.) paralleled by a rapid increase in nitric oxide [116]. Inhibition of Src kinase decreased eNOS and Akt phosphorylation in response to alogliptin, in contrast to a lack of any effect on insulin mediated activation of the eNOSAkt, suggesting that alogliptin mediates vasodilation through Src kinase mediated effects on eNOS-Akt. DPP4 has also been shown to assist in angiogenesis by promoting EPCs in a GLP-1-independent pathway. Stromal derived factor$1 \alpha$ (SDF-1 $\alpha$ ), a known substrate of DPP4, is a regulator of EPCs. By comparing four weeks of sitagliptin versus no additional treatment added to baseline metformin and/or sulfonylurea therapy in 32 diabetic patients, Fadini and coworkers demonstrated that patients with DPP4 inhibition had a 2-fold increase of EPCs and a 50\% increase of SDF- $1 \alpha$ [117].

DPP4 may also affect cardiovascular function through regulation of inflammation. DPP4 is highly expressed on many inflammatory cells such as $\mathrm{T}$ cells and regulates their biological function [49]. Both enzymatic and nonenzymatic functions of DPP4 play an important role in T cell activation. $\mathrm{T}$ cell activation can be blocked by enzymatic inhibition of DPP4 $[118,119]$. Suppression of dipeptidyl-peptidase activity of DPP4 resulted in a reduced production of cytokines including IL-2, IL-10, IL-12, and IFN- $\gamma$ by peripheral blood mononuclear cells and $\mathrm{T}$ cells $[118,120,121]$. TGF- $\beta 1$, an immunosuppressive cytokine, was shown to be upregulated by DPP4 inhibition $[121,122]$. T cells transfected with mutant DPP4 devoid of enzymatic activity displayed reduced 
activation compared to those cells transfected with wildtype DPP4 [123]. Consistent with this finding, the addition of soluble DPP4 promoted the recall antigen-induced proliferation of peripheral blood lymphocytes, while soluble DPP4 mutant without enzymatic activity did not, providing a direct evidence that enzymatic activity of DPP4 is involved in the T cell activation [124]. As mentioned previously, DPP4 also promotes inflammation through catalytic independent mechanisms such as interactions with ADA and caveolin1 [47]. However, there were also reports indicating that DPP4 may negatively regulate immune response. Mice deficient for DPP4 showed enhanced severity of autoimmune encephalomyelitis and reduced TGF $\beta$ and increased production of IFN $\gamma$ and TNF $\alpha$ when immunized with myelin oligodendrocyte glycoprotein. Inhibition of DPP4 activity has also been shown to enhance hematopoiesis by preserving colony-stimulating factor activity [125-127]. Those immunosuppressive functions may at least in part explain the lack of improvement in cardiovascular endpoints on T2DM patients with DPP4i.

4.3. Role of DPP4 in Cardiovascular Disease. There is good evidence that DPP4 inhibition mediates protective effect on myocardial infarction, hypertension, and atherosclerosis. Survival rate and infarct size significantly improved in $D p p 4^{-/-}$mice after LAD ligation, accompanied by enhanced prosurvival signal pathways, such as pAKT, pGSK3 $\beta$, and atrial natriuretic peptide in cardiac tissue [1]. Pharmacologic inhibition with sitagliptin also enhances expression of cardioprotective proteins and improved functional recovery after I/R injury in the murine heart [1]. Several studies in animal models support a favorable effect of DPP4 inhibition in improving endothelial function and blood pressure [116, $128,129]$. Saxagliptin treatment, for instance, has been shown to reduce blood pressure in the spontaneously hypertensive rat, an effect that was accompanied by an increase in aortic and glomerular NO release with comparable reductions in peroxynitrite levels [130]. In contrast to the positive effects in animal experiments, the effects of DPP4i on endothelial function in humans have not always been positive. In a double blind study in T2DM, treatment with vildagliptin for 4 weeks improved forearm blood flow in response to intra-arterially delivered acetylcholine [131]. In contrast, 2 studies using flow mediated dilation (FMD) of the brachial artery have shown diametrically opposite results. In one study, 2 DPP4i (sitagliptin and alogliptin) actually appeared to worsen FMD when used to treat T2DM [132]. In another study, sitagliptin improved FMD in association with an increase in $\mathrm{CD} 34^{+}$cells [133].

Both GLP-1 agonism and DPP4 inhibition reduce postprandial triacylglycerol and ApoB-48 in rodents [111, 112]. Human studies have shown that GLP-1 infusion $(1.2 \mathrm{pmol} / \mathrm{kg} / \mathrm{min})$ for hours suppresses postprandial plasma triacylglycerol and free fatty acid levels [113]. A shortterm treatment of GLP-1 ( $25 \mathrm{nmol}$ sc injection before meals for 5 days) decreased plasma VLDL-triacylglycerol by $38 \%$ [114]. Continuous infusion of exendin- 4 for 4 weeks reduces neointimal formation [108], foam cell formation [109], and atherosclerotic lesion size $[109,110]$ in mice. By providing 12 weeks of alogliptin treatment, Shah et al. demonstrated that DPP4 inhibition reduced atherosclerotic plaque and vascular inflammation in atherosclerosis prone $\mathrm{Ldlr}^{-/-}$and $A p o E^{-/-}$ mice [134]. However, human studies reveal contradictory results on the cardiovascular effects of DPP4 inhibitors. Patil et al. reported in a recent meta-analysis including 18 randomized clinical trials and 4,988 patients on DPP4 inhibition therapy and 3,546 patients on control treatment (other diabetic treatments or placebo) and demonstrated that DPP4 inhibitors are safe from a cardiovascular standpoint and have beneficial effects on cardiovascular events compared to other diabetic medications and placebo [3]. Another meta-analysis with 70 trials and 41,959 patients performed by Monami et al. also suggested that DPP4 inhibition reduced cardiovascular risk and all-cause mortality in diabetic patients [135]. In contrast, a more recent meta-analysis of 50 trials with 55,141 participants reported that DPP4 inhibitors have no difference in all-cause mortality, CV mortality, acute coronary syndrome, or stroke compared with placebo. Furthermore, DPP4 inhibitors showed a statistically significant increase in heart failure outcomes $(\mathrm{RR}=1.16$; 95\% CI 1.01-1.33; $P=0.04)$ [136]. The association between DPP4 inhibition and increased risk of heart failure is also supported by another meta-analysis by Monami in 2014 [137]. More importantly, the results from two large scale clinical trials completed recently also did not support the cardioprotective effect of DPP4 inhibition in humans.

\subsection{Results from Large Scale Clinical Trials of DPP4 Inhibitors.} There are several phase- 3 or phase- 4 clinical trials assessing the cardiovascular effect of DPP4i. These trials include EXAMINE (EXamination of cArdiovascular outcoMes with alogliptIN versus standard of carE in patients with T2DM and acute coronary syndrome) on alogliptin and SAVORTIMI 53 (Saxagliptin Assessment of Vascular Outcomes Recorded in Patients With Diabetes Mellitus-Thrombolysis in Myocardial Infarction 53 trial) which have been completed. The ongoing studies include TECOS (ClinicalTrials.gov Identifier: NCT00790205) on sitagliptin, CAROLINA (ClinicalTrials.gov Identifier: NCT01243424) on linagliptin, CARMELINA (ClinicalTrials.gov Identifier: NCT01897532) on linagliptin, MK-3102-015 AM1 (ClinicalTrials.gov Identifier: NCT01697592) on omarigliptin (MK3102), and MK3102-018 (ClinicalTrials.gov Identifier: NCT01703208) on omarigliptin.

In the EXAMINE study, 5,380 diabetic patients with a recent (<90 days) myocardial infarction or unstable angina requiring hospitalization were randomized to the treatment of alogliptin or placebo. The patients were followed for a median period of 18 months. Although a safety trial was not designed to answer questions on efficacy, alogliptin treatment did not improve the combined outcome of primary endpoints including death from cardiovascular causes, nonfatal myocardial infarction, and nonfatal stroke [4]. There was a trend towards reduction in cardiovascular death albeit nonstatistically significant. A total of 16,492 subjects with HbA1c $6.5-12 \%$ and one of the following cardiovascular risks: a history of MI, atherosclerosis, hypertension, smoking, or dyslipidemia, were recruited in SAVOR-TIMI 53 to evaluate the 
effect of saxagliptin on cardiovascular outcomes. The patients were randomized to saxagliptin or placebo group. Additional antidiabetic agents were prescribed throughout the study. Median follow-up time was 2.1 years and maximum was 2.9 years. In consistency with the results from EXAMINE, no improvements in cardiovascular outcomes were observed in saxagliptin treatment group compared to placebo-treated patients. It is noteworthy that the hospitalization rate for heart failure was higher in saxagliptin-treated subjects (3.5\% versus 2.8\%; hazard ratio, 1.27 ; $95 \% \mathrm{CI}, 1.07$ to $1.51 ; P=0.007$ ) [5]. No differences in multiple other safety endpoints (such as pancreatitis, cancer, and hypoglycemia) were observed across groups in both SAVOR-TIMI and EXAMINE trials. These trials suggest that catalytic inhibition of DPP4 is basically safe from a cardiovascular standpoint but also does not improve cardiovascular endpoints at least in the short term. It must be noted that the median follow-up period for EXAMINE and SAVOR-TIMI 53 was 1.5 years and 2.1 years, respectively, and a longer follow-up period may be necessary to further confirm the results. At least from the results of current large scale trials, it is suggested that catalytic inhibition alone is insufficient to improve cardiovascular outcomes. The other ongoing trials assessing the cardiovascular safety of DPP4i may provide further insights into the cardiovascular effect of DPP4.

4.5. Effect of DPP4 Inhibition on Heart Failure. Animal studies have suggested that DPP4 inhibition improved cardiac function and survival rate of heart failure. Gomez et al. reported that DPP4 activity was positively associated with body weight in adult dog and was significantly higher in heart failure class 1 compared with healthy heart and heart failure class 3, demonstrating that DPP4 might be involved in the early stage of heart failure [138]. In a pressureoverload-induced heart failure animal model (transverse aortic constriction, TAC), Takahashi reported that vildagliptin ameliorated TAC-induced left ventricular enlargement and dysfunction and improved survival rate on day 28 (TAC with vildagliptin, 67.5\%; TAC without vildagliptin, $41.5 \% ; P<$ 0.05). In accordance with this, Shigeta et al. demonstrated that both pharmacological and genetic DPP4 inhibition reversed diabetic diastolic left ventricular dysfunction and pressure-overload-induced left ventricular dysfunction [2].

Improved left ventricular function assessed by ejection fraction, mitral annular systolic velocity, and peak systolic velocity was also observed in humans with DPP4 inhibition (sitagliptin, single dose or 4 weeks of treatment) [34, 40]. GLP-1 agonists have also been shown to increase left ventricular ejection fraction [139-141] (all in short term), although there have been inconsistencies $[142,143]$. Despite the potential benefits in improving cardiac function from short-term use of DPP4i and GLP-1 analogs, reports on long-term cardiovascular effect of DPP4i and GLP-1 analogs are limited. Surprisingly, Scirica et al. reported an increased hospital admission rate for heart failure in saxagliptin-treated patients compared with placebo (3.5\% versus $2.8 \%$; hazard ratio, 1.27; 95\% CI, 1.07 to $1.51 ; P=0.007)$ in SAVOR-TIMI
53 trial [5], raising the question whether DPP4i increase the risk for heart failure [144]. In a subsequent meta-analysis including 84 trials and 69,615 patients, Monami et al. reported that DPP4i (including vildagliptin, sitagliptin, saxagliptin, alogliptin, linagliptin, and dutogliptin) increased the overall risk for heart failure with an OR of 1.19 (95\% CI: 1.03 to 1.37; $P$ $=0.015)$ although these results were heavily influenced by the SAVOR-TIMI 53 results [137]. Interestingly, another metaanalysis which pooled 20 randomized controlled studies and 9,156 patients to assess the cardiovascular safety of saxagliptin reported that saxagliptin did not increase the incidence rates for cardiovascular events including heart failure, with an incidence rate ratio of 0.55 (95\% CI: 0.27 to 1.12 ) for heart failure [145]. In a study published July 2014, Weir et al. further evaluated the effect of sitagliptin (Januvia) on cardiovascular endpoints (all-cause hospital admission/death as well as heart-failure-specific hospitalization/death in 7,620 diabetic patients recently diagnosed with heart failure) [146]. Although sitagliptin treatment did not increase the risk for primary endpoints or each component (hospital admission or death), it was noted to be associated with increased risk for heart failure hospitalization (12.5\% versus $9.0 \%$; OR: 1.84; 95\% CI: 1.16-2.92). The absolute risks associated with DPP4i for heart failure are small. One limitation of this metaanalysis should not be overlooked with the principal criticism being that they include studies that were never designed for cardiovascular signals [147].

Are there risk factors that may identify patients at risk for this small risk seen with saxagliptin? In the SAVOR-TIMI 53 trial, Scirica et al. reported that patients with increased risk for hospitalization for heart failure had either prior heart failure or elevated levels of natriuretic peptides or chronic kidney disease. However, the risks of the primary and secondary endpoints were similar between treatment groups even in patients at high risk for hospitalization for heart failure [148], suggesting that DPP4 inhibition by saxagliptin does not increase death, myocardial infarction, or stroke even in those with increased risk for heart failure [149]. Therefore, these recent findings may not limit the use of DPP4i in T2DM patients with cardiovascular disease. However, DPP4i should be used with caution in T2DM patients with increased vulnerability to DPP4 inhibition-associated heart failure, especially with saxagliptin such as history of heart failure or chronic kidney disease. The ongoing studies such as TECOS, CARMELINA, and CAROLINA should be informative of additional risks posed by these agents as a class.

\section{Safety of DPP4i}

Early studies on the safety suggested a well tolerability of DPP4i with only some minor side effects such as gastrointestinal reaction (nausea, vomiting, diarrhea, etc.), flulike symptoms, and skin reactions [63, 150, 151]. More importantly, they showed no weight gain and hypoglycemic risk compared to other oral antidiabetic medications [152]. Considering the diverse functions of DPP4, the safety of long-term usage of DPP4i on immune function such as antitumor and anti-infection was questioned [153]. An altered 
expression level of DPP4 has been reported in many types of cancer [153]. An increase in pancreatic cancer was noted in patients taking sitagliptin or exenatide compared with other therapies as evidenced by an evaluation of US FDA adverse event database [154]. But the incidence of all other cancers was similar between sitagliptin group and control drugs [154]. Another evaluation of the German adverse event database, in contrast, showed no significant association between pancreatic cancer and DPP4i [155]. Several metaanalysis reports indicate an increased risk of infection such as nasopharyngitis and urinary tract infection in patients on DPP4i [156, 157]. However, there were also contradictory reports on infections. Monami et al. reported in a metaanalysis that there was a significant increase in the risk of nasopharyngitis with sitagliptin (Mantel-Haenszel odds ratio (MH-OR): 1.43 ; 95\% CI: $1.07-1.91 ; P=0.017$ ), but not with vildagliptin. No significant associations with upper respiratory tract infection and urinary tract infection were observed. The actual incidence of other infections was lower than in comparator groups [152].

There were also some studies raising concerns that incretin-based therapy may potentially contribute to pancreatitis $[158,159]$. However, there are very limited clinical data examining the risk of DPP4i on pancreatitis and the conclusion remains uncertain [160]. A meta-analysis including 134 trials on DPP4i and pancreatitis risk showed no significant increase of pancreatitis with DPP4i $(\mathrm{MH}-$ OR: 0.93 ; 95\% CI: $0.51-1.69 ; P=0.82$ ) [161]. It is noteworthy that the number of observed cases was small and further investigations are needed to confirm the result. Elashoff et al. reported a 6-fold increase of pancreatitis in patients treated with sitagliptin compared with patients treated with control antidiabetic drugs [154]. In contrast, a recent case-control study including 12,868 patients' first-time hospitalization for acute pancreatitis from 2005 to 2012 also reveals no associations between DPP4i and acute pancreatitis [162].

\section{Conclusion}

The development and application of specific DPP4i in clinic reemphasized the importance of DPP4 in both physiological and pathological processes. Recent studies suggest that DPP4i are safe from cardiovascular perspective although no significant improvement was observed in cardiovascular endpoints on T2DM patients with antidiabetic medications. However, it must be acknowledged that the durations of these two trials are less than 5 years and all subjects were on medications such as statins which may interfere with the cardiovascular effects of DPP4i. Notably, at least one trial showed an increase of heart failure hospitalization in T2DM patients with prior heart failure or chronic kidney disease, suggesting that DPP4i should be used in caution in those patients. The absolute risks for heart failure agents are small with these agents and it must be acknowledged that not only diabetes but other therapies used for glycemia control such as sulfonylureas and thiazolidinediones also increase the risk for heart failure. Further studies are required to investigate the exact role of DPP4i, particularly their catalytic independent activity in cardiovascular disease.

\section{Conflict of Interests}

Drs. Jixin Zhong, Quan Gong, Aditya Goud, and Srividya Srinivasamaharaj declare that there is no conflict of interests. Dr. Sanjay Rajagopalan has received funding from Takeda Pharmaceuticals.

\section{Acknowledgments}

This work was supported by grants from AHA (13POST17210033) and NSFC (81101553) to Dr. Zhong.

\section{References}

[1] M. Sauvé, K. Ban, M. Abdul Momen et al., "Genetic deletion or pharmacological inhibition of dipeptidyl peptidase-4 improves cardiovascular outcomes after myocardial infarction in mice," Diabetes, vol. 59, no. 4, pp. 1063-1073, 2010.

[2] T. Shigeta, M. Aoyama, Y. K. Bando et al., "Dipeptidyl peptidase-4 modulates left ventricular dysfunction in chronic heart failure via angiogenesis-dependent and -independent actions," Circulation, vol. 126, no. 15, pp. 1838-1851, 2012.

[3] H. R. Patil, F. J. Al Badarin, H. A. Al Shami et al., "Meta-analysis of effect of dipeptidyl peptidase-4 inhibitors on cardiovascular risk in type 2 diabetes mellitus," The American Journal of Cardiology, vol. 110, no. 6, pp. 826-833, 2012.

[4] W. B. White, C. P. Cannon, S. R. Heller et al., "Alogliptin after acute coronary syndrome in patients with type 2 diabetes," The New England Journal of Medicine, vol. 369, no. 14, pp. 1327-1335, 2013.

[5] B. M. Scirica, D. L. Bhatt, E. Braunwald et al., "Saxagliptin and cardiovascular outcomes in patients with type 2 diabetes mellitus," The New England Journal of Medicine, vol. 369, no. 14, pp. 1317-1326, 2013.

[6] E. Richard, F. X. Arredondo-Vega, I. Santisteban, S. J. Kelly, D. D. Patel, and M. S. Hershfield, "The binding site of human adenosine deaminase for CD26/dipeptidyl peptidase IV: the Arg142Gln mutation impairs binding to CD26 but does not cause immune deficiency," Journal of Experimental Medicine, vol. 192, no. 9, pp. 1223-1236, 2000.

[7] R.-P. Dong, K. Tachibana, M. Hegen et al., "Determination of adenosine deaminase binding domain on CD26 and its immunoregulatory effect on T cell activation," The Journal of Immunology, vol. 159, no. 12, pp. 6070-6076, 1997.

[8] C. A. Abbott, G. W. McCaughan, M. T. Levy, W. B. Church, and M. D. Gorrell, "Binding to human dipeptidyl peptidase IV by adenosine deaminase and antibodies that inhibit ligand binding involves overlapping, discontinuous sites on a predicted $\beta$ propeller domain," European Journal of Biochemistry, vol. 266, no. 3, pp. 798-810, 1999.

[9] M. D. Gorrell, "Dipeptidyl peptidase IV and related enzymes in cell biology and liver disorders," Clinical Science, vol. 108, no. 4, pp. 277-292, 2005.

[10] Y. Kirino, Y. Sato, T. Kamimoto, K. Kawazoe, and K. Minakuchi, "Altered dipeptidyl peptidase-4 activity during the progression of hyperinsulinemic obesity and islet atrophy in spontaneously late-stage type 2 diabetic rats," The American Journal of Physiology-Endocrinology and Metabolism, vol. 300, no. 2, pp. E372-E379, 2011.

[11] T. Andrieu, V. Thibault, I. Malet et al., "Similar increased serum dipeptidyl peptidase IV activity in chronic hepatitis $\mathrm{C}$ and other 
viral infections," Journal of Clinical Virology, vol. 27, no. 1, pp. 59-68, 2003.

[12] A. Šedo, J. Stremenová, P. Bušek, and J. S. Duke-Cohan, "Dipeptidyl peptidase-IV and related molecules: markers of malignancy?" Expert Opinion on Medical Diagnostics, vol. 2, no. 6, pp. 677-689, 2008.

[13] B. Bauvois, M. Djavaheri-Mergny, D. Rouillard, J. Dumont, and J. Wietzerbin, "Regulation of CD26/DPPIV gene expression by interferons and retinoic acid in tumor B cells," Oncogene, vol. 19, no. 2, pp. 265-272, 2000.

[14] R. H. Erickson, R. S. Lai, and Y. S. Kim, "Role of hepatocyte nuclear factor $1 \alpha$ and $1 \beta$ in the transcriptional regulation of human dipeptidyl peptidase IV during differentiation of Caco2 cells," Biochemical and Biophysical Research Communications, vol. 270, no. 1, pp. 235-239, 2000.

[15] F. J. Salgado, E. Vela, M. Martín, R. Franco, M. Nogueira, and O. J. Cordero, "Mechanisms of CD26/dipeptidyl peptidase IV cytokine-dependent regulation on human activated lymphocytes," Cytokine, vol. 12, no. 7, pp. 1136-1141, 2000.

[16] E. Nemoto, S. Sugawara, H. Takada, S. Shoji, and H. Horiuch, "Increase of CD26/dipeptidyl peptidase IV expression on human gingival fibroblasts upon stimulation with cytokines and bacterial components," Infection and Immunity, vol. 67, no. 12, pp. 6225-6233, 1999.

[17] E. N. Arwert, R. A. Mentink, R. R. Driskell et al., "Upregulation of CD26 expression in epithelial cells and stromal cells during wound-induced skin tumour formation," Oncogene, vol. 31, no. 8, pp. 992-1000, 2012.

[18] B. Bengsch, B. Seigel, T. Flecken, J. Wolanski, H. E. Blum, and R. Thimme, "Human Th17 cells express high levels of enzymatically active dipeptidylpeptidase IV (CD26)," The Journal of Immunology, vol. 188, no. 11, pp. 5438-5447, 2012.

[19] S. L. Conarello, Z. Li, J. Ronan et al., "Mice lacking dipeptidyl peptidase IV are protected against obesity and insulin resistance," Proceedings of the National Academy of Sciences of the United States of America, vol. 100, no. 11, pp. 6825-6830, 2003.

[20] D. Marguet, L. Baggio, T. Kobayashi et al., "Enhanced insulin secretion and improved glucose tolerance in mice lacking CD26," Proceedings of the National Academy of Sciences of the United States of America, vol. 97, no. 12, pp. 6874-6879, 2000.

[21] D. J. Drucker and M. A. Nauck, "The incretin system: glucagonlike peptide-1 receptor agonists and dipeptidyl peptidase-4 inhibitors in type 2 diabetes," The Lancet, vol. 368, no. 9548, pp. 1696-1705, 2006.

[22] J. Zhong, A. Maiseyeu, S. N. Davis, and S. Rajagopalan, "DPP4 in cardiometabolic disease: recent insights from the laboratory and clinical trials of DPP4 inhibition," Circulation Research, vol. 116, no. 8, pp. 1491-1504, 2015.

[23] E. E. Mulvihill and D. J. Drucker, "Pharmacology, physiology, and mechanisms of action of dipeptidyl peptidase-4 inhibitors," Endocrine Reviews, vol. 35, pp. 992-1019, 2014.

[24] J. Kameoka, T. Tanaka, Y. Nojima, S. F. Schlossman, and C. Morimoto, "Direct association of adenosine deaminase with a T cell activation antigen, CD26," Science, vol. 261, no. 5120, pp. 466-469, 1993.

[25] E. Muñoz, M. V. Blazquez, J. A. Madueño, G. Rubio, and J. Peña, "CD26 induces T-cell proliferation by tyrosine protein phosphorylation,” Immunology, vol. 77, no. 1, pp. 43-50, 1992.

[26] M. Hegen, J. Kameoka, R.-P. Dong, S. F. Schlossman, and C. Morimoto, "Cross-linking of CD26 by antibody induces tyrosine phosphorylation and activation of mitogen-activated protein kinase," Immunology, vol. 90, no. 2, pp. 257-264, 1997.

[27] Y. Torimoto, N. H. Dang, E. Vivier, T. Tanaka, S. F. Schlossman, and C. Morimoto, "Coassociation of CD26 (dipeptidyl peptidase IV) with CD45 on the surface of human T lymphocytes," Journal of Immunology, vol. 147, no. 8, pp. 2514-2517, 1991.

[28] G. Vanham, L. Kestens, I. De Meester et al., "Decreased expression of the memory marker CD26 on both $\mathrm{CD} 4^{+}$and $\mathrm{CD} 8^{+}$ T lymphocytes of HIV-infected subjects," Journal of Acquired Immune Deficiency Syndromes, vol. 6, no. 7, pp. 749-757, 1993.

[29] D. A. Hafler, D. A. Fox, D. Benjamin, and H. L. Weiner, "Antigen reactive memory $\mathrm{T}$ cells are defined by Ta1," The Journal of Immunology, vol. 137, no. 2, pp. 414-418, 1986.

[30] K. Ohnuma, M. Uchiyama, T. Yamochi et al., "Caveolin-1 triggers T-cell activation via CD26 in association with CARMAl," The Journal of Biological Chemistry, vol. 282, no. 13, pp. 1011710131, 2007.

[31] CDC, Middle East Respiratory Syndrome (MERS), Centers for Disease Control and Prevention (CDC), Atlanta, Ga, USA, 2015, http://www.cdc.gov/coronavirus/mers/.

[32] V. Stalin Raj, S. L. Smits, L. B. Provacia et al., "Adenosine deaminase acts as a natural antagonist for dipeptidyl peptidase 4-mediated entry of the middle East respiratory syndrome coronavirus," Journal of Virology, vol. 88, no. 3, pp. 1834-1838, 2014.

[33] G. Lu, Y. Hu, Q. Wang et al., "Molecular basis of binding between novel human coronavirus MERS-CoV and its receptor CD26," Nature, vol. 500, no. 7461, pp. 227-231, 2013.

[34] A. S. Cockrell, K. M. Peck, B. L. Yount et al., "Mouse dipeptidyl peptidase 4 is not a functional receptor for Middle East respiratory syndrome coronavirus infection," Journal of Virology, vol. 88, no. 9, pp. 5195-5199, 2014.

[35] C. Callebaut, B. Krust, E. Jacotot, and A. G. Hovanessian, "T cell activation antigen, CD26, as a cofactor for entry of HIV in CD4+ cells," Science, vol. 262, no. 5142, pp. 2045-2050, 1993.

[36] G. Alkhatib, C. Combadiere, C. C. Broder et al., "CC CKR5: a RANTES, MIP- $1 \alpha$, MIP- $1 \beta$ receptor as a fusion cofactor for macrophage-tropic HIV-1," Science, vol. 272, no. 5270, pp. 19551958, 1996.

[37] H. Deng, R. Liu, W. Ellmeier et al., "Identification of a major co-receptor for primary isolates of HIV-1," Nature, vol. 381, no. 6584, pp. 661-666, 1996.

[38] T. Dragic, V. Litwin, G. P. Allaway et al., "HIV-1 entry into $\mathrm{CD} 4^{+}$cells is mediated by the chemokine receptor CC-CKR-5," Nature, vol. 381, no. 6584, pp. 667-673, 1996.

[39] H. Choe, M. Farzan, Y. Sun et al., "The $\beta$-chemokine receptors CCR3 and CCR5 facilitate infection by primary HIV-1 isolates," Cell, vol. 85, no. 7, pp. 1135-1148, 1996.

[40] L. Wu, W. A. Paxton, N. Kassam et al., "CCR5 levels and expression pattern correlate with infectability by macrophagetropic HIV-1, in vitro," Journal of Experimental Medicine, vol. 185, no. 9, pp. 1681-1691, 1997.

[41] K. Ohnuma, Y. Munakata, T. Ishii et al., "Soluble CD26/ dipeptidyl peptidase IV induces T cell proliferation through CD86 up-regulation on APCs," The Journal of Immunology, vol. 167, no. 12, pp. 6745-6755, 2001.

[42] K. Ohnuma, T. Yamochi, M. Uchiyama et al., "CD26 upregulates expression of CD86 on antigen-presenting cells by means of caveolin-1," Proceedings of the National Academy of Sciences of the United States of America, vol. 101, no. 39, pp. 14186-14191, 2004. 
[43] K. Ohnuma, T. Yamochi, M. Uchiyama et al., "CD26 mediates dissociation of Tollip and IRAK-1 from caveolin-1 and induces upregulation of CD86 on antigen-presenting cells," Molecular and Cellular Biology, vol. 25, no. 17, pp. 7743-7757, 2005.

[44] K. Ohnuma, N. Takahashi, T. Yamochi, O. Hosono, N. H. Dang, and C. Morimoto, "Role of CD26/dipeptidyl peptidase IV in human T cell activation and function," Frontiers in Bioscience, vol. 13, no. 6, pp. 2299-2310, 2008.

[45] K. Ohnuma, H. Inoue, M. Uchiyama et al., "T-cell activation via CD26 and caveolin-1 in rheumatoid synovium," Modern Rheumatology, vol. 16, no. 1, pp. 3-13, 2006.

[46] K. Loster, K. Zeilinger, D. Schuppan, and W. Reutter, “The cysteine-rich region of dipeptidyl, peptidase IV (CD 26) is the collagen-binding site," Biochemical and Biophysical Research Communications, vol. 217, no. 1, pp. 341-348, 1995.

[47] J. Zhong, X. Rao, and S. Rajagopalan, "An emerging role of dipeptidyl peptidase 4 (DPP4) beyond glucose control: potential implications in cardiovascular disease," Atherosclerosis, vol. 226, no. 2, pp. 305-314, 2013.

[48] E. Mannucci, L. Pala, S. Ciani et al., "Hyperglycaemia increases dipeptidyl peptidase IV activity in diabetes mellitus," Diabetologia, vol. 48, no. 6, pp. 1168-1172, 2005.

[49] J. Ryskjær, C. F. Deacon, R. D. Carr et al., "Plasma dipeptidyl peptidase-IV activity in patients with type-2 diabetes mellitus correlates positively with HbAlc levels, but is not acutely affected by food intake," European Journal of Endocrinology, vol. 155, no. 3, pp. 485-493, 2006.

[50] R. Lugari, A. Dei Cas, D. Ugolotti et al., "Glucagon-like peptide 1 (GLP-1) secretion and plasma dipeptidyl peptidase IV (DPP-IV) activity in morbidly obese patients undergoing biliopancreatic diversion," Hormone and Metabolic Research, vol. 36, no. 2, pp. 111-115, 2004.

[51] S. A. Lee, Y. R. Kim, E. J. Yang et al., "CD26/DPP4 levels in peripheral blood and $\mathrm{T}$ cells in patients with type 2 diabetes mellitus," Journal of Clinical Endocrinology and Metabolism, vol. 98, no. 6, pp. 2553-2561, 2013.

[52] A. M. McKillop, N. A. Duffy, J. R. Lindsay, F. P. M. O’Harte, P. M. Bell, and P. R. Flatt, "Decreased dipeptidyl peptidase-IV activity and glucagon-like peptide-1(7-36)amide degradation in type 2 diabetic subjects," Diabetes Research and Clinical Practice, vol. 79, no. 1, pp. 79-85, 2008.

[53] J. M. Lenhard, D. K. Croom, and D. T. Minnick, "Reduced serum dipeptidyl peptidase-IV after metformin and pioglitazone treatments," Biochemical and Biophysical Research Communications, vol. 324, no. 1, pp. 92-97, 2004.

[54] J. R. Lindsay, N. A. Duffy, A. M. McKillop et al., "Inhibition of dipeptidyl peptidase IV activity by oral metformin in type 2 diabetes," Diabetic Medicine, vol. 22, no. 5, pp. 654-657, 2005.

[55] B. D. Green, N. Irwin, N. A. Duffy, V. A. Gault, F. P. M. O’Harte, and P. R. Flatt, "Inhibition of dipeptidyl peptidase-IV activity by metformin enhances the antidiabetic effects of glucagon-like peptide-1," European Journal of Pharmacology, vol. 547, no. 1-3, pp. 192-199, 2006.

[56] M. Miyazaki, M. Kato, K. Tanaka et al., "Increased hepatic expression of dipeptidyl peptidase- 4 in non-alcoholic fatty liver disease and its association with insulin resistance and glucose metabolism," Molecular Medicine Reports, vol. 5, no. 3, pp. 729733, 2012.

[57] J. R. Ussher and D. J. Drucker, "Cardiovascular biology of the incretin system," Endocrine Reviews, vol. 33, no. 2, pp. 187-215, 2012.
[58] D. J. Drucker, “The biology of incretin hormones," Cell Metabolism, vol. 3, no. 3, pp. 153-165, 2006.

[59] T. J. Kieffer, C. H. S. McIntosh, and R. A. Pederson, "Degradation of glucose-dependent insulinotropic polypeptide and truncated glucagon-like peptide 1 in vitro and in vivo by dipeptidyl peptidase IV," Endocrinology, vol. 136, no. 8, pp. 3585-3596, 1995.

[60] L. Pridal, C. F. Deacon, O. Kirk, J. V. Christensen, R. D. Carr, and J. J. Holst, "Glucagon-like peptide-1(7-37) has a larger volume of distribution than glucagon-like peptide-1(7-36)amide in dogs and is degraded more quickly in vitro by dog plasma," European Journal of Drug Metabolism and Pharmacokinetics, vol. 21, no. 1, pp. 51-59, 1996.

[61] L. L. Baggio and D. J. Drucker, "Biology of incretins: GLP-1 and GIP," Gastroenterology, vol. 132, no. 6, pp. 2131-2157, 2007.

[62] S. E. Inzucchi and D. K. McGuire, "New drugs for the treatment of diabetes part II: incretin-based therapy and beyond," Circulation, vol. 117, no. 4, pp. 574-584, 2008.

[63] I. Raz, M. Hanefeld, L. Xu, C. Caria, D. Williams-Herman, and H. Khatami, "Efficacy and safety of the dipeptidyl peptidase4 inhibitor sitagliptin as monotherapy in patients with type 2 diabetes mellitus," Diabetologia, vol. 49, no. 11, pp. 2564-2571, 2006.

[64] A.-M. Lambeir, S. Scharpé, and I. De Meester, "DPP4 inhibitors for diabetes-what next?" Biochemical Pharmacology, vol. 76, no. 12, pp. 1637-1643, 2008.

[65] T. Jose and S. E. Inzucchi, "Cardiovascular effects of the DPP-4 inhibitors," Diabetes and Vascular Disease Research, vol. 9, no. 2, pp. 109-116, 2012.

[66] K. Traynor, "FDA approves saxagliptin for type 2 diabetes," American Journal of Health-System Pharmacy, vol. 66, no. 17, p. 1513, 2009.

[67] K. Traynor, "Linagliptin approved for type 2 diabetes," The American Journal of Health-System Pharmacy, vol. 68, no. 12, p. 1059, 2011.

[68] A. H. Barnett, "Linagliptin: a novel dipeptidyl peptidase 4 inhibitor with a unique place in therapy," Advances in Therapy, vol. 28, no. 6, pp. 447-459, 2011.

[69] G. S. Hotamisligil, "Inflammation and metabolic disorders," Nature, vol. 444, no. 7121, pp. 860-867, 2006.

[70] H. Sell, C. Habich, and J. Eckel, "Adaptive immunity in obesity and insulin resistance," Nature Reviews Endocrinology, vol. 8, no. 12, pp. 709-716, 2012.

[71] M. S. Hershfield, "New insights into adenosine-receptormediated immunosuppression and the role of adenosine in causing the immunodeficiency associated with adenosine deaminase deficiency," European Journal of Immunology, vol. 35, no. 1, pp. 25-30, 2005.

[72] A. Mortellaro, R. J. Hernandez, M. M. Guerrini et al., "Ex vivo gene therapy with lentiviral vectors rescues adenosine deaminase (ADA)-deficient mice and corrects their immune and metabolic defects," Blood, vol. 108, no. 9, pp. 2979-2988, 2006.

[73] J. J. Sanchez, G. Monaghan, C. Børsting, G. Norbury, N. Morling, and H. B. Gaspar, "Carrier frequency of a nonsense mutation in the adenosine deaminase (ADA) gene implies a high incidence of ADA-deficient severe combined immunodeficiency (SCID) in Somalia and a single, common haplotype indicates common ancestry," Annals of Human Genetics, vol. 71, no. 3, pp. 336-347, 2007.

[74] S. Deaglio, K. M. Dwyer, W. Gao et al., "Adenosine generation catalyzed by CD39 and CD73 expressed on regulatory T cells 
mediates immune suppression," The Journal of Experimental Medicine, vol. 204, no. 6, pp. 1257-1265, 2007.

[75] R. Resta, Y. Yamashita, and L. F. Thompson, "Ecto-enzyme and signaling functions of lymphocyte CD73," Immunological Reviews, vol. 161, pp. 95-109, 1998.

[76] R.-P. Dong, J. Kameoka, M. Hegen et al., "Characterization of adenosine deaminase binding to human CD26 on T cells and its biologic role in immune response," Journal of Immunology, vol. 156, no. 4, pp. 1349-1355, 1996.

[77] J. Zhong, X. Rao, J. Deiuliis et al., "A potential role for dendritic cell/macrophage-expressing DPP4 in obesity-induced visceral inflammation," Diabetes, vol. 62, no. 1, pp. 149-157, 2013.

[78] M. Engel, T. Hoffmann, L. Wagner et al., “The crystal structure of dipeptidyl peptidase IV (CD26) reveals its functional regulation and enzymatic mechanism," Proceedings of the National Academy of Sciences of the United States of America, vol. 100, no. 9, pp. 5063-5068, 2003.

[79] S. Reardon, "Biologists make first mouse model for MERS," Nature, 2014.

[80] B. P. Bullock, R. S. Heller, and J. F. Habener, "Tissue distribution of messenger ribonucleic acid encoding the rat glucagon-like peptide-1 receptor," Endocrinology, vol. 137, no. 7, pp. 2968-2978, 1996.

[81] B. Thorens, "Expression cloning of the pancreatic $\beta$ cell receptor for the gluco-incretin hormone glucagon-like peptide 1," Proceedings of the National Academy of Sciences of the United States of America, vol. 89, no. 18, pp. 8641-8645, 1992.

[82] K. E. Mayo, L. J. Miller, D. Bataille et al., "International Union of Pharmacology. XXXV. The glucagon receptor family," Pharmacological Reviews, vol. 55, no. 1, pp. 167-194, 2003.

[83] J. Buteau, M. L. Spatz, and D. Accili, “Transcription factor FoxO1 mediates glucagon-like peptide-1 effects on pancreatic beta-cell mass," Diabetes, vol. 55, no. 5, pp. 1190-1196, 2006.

[84] H. Hui, A. Nourparvar, X. Zhao, and R. Perfetti, “Glucagonlike peptide-1 inhibits apoptosis of insulin-secreting cells via a cyclic 5 -adenosine monophosphate-dependent protein kinase A- and a phosphatidylinositol 3-kinase-dependent pathway," Endocrinology, vol. 144, no. 4, pp. 1444-1455, 2003.

[85] T. Nyström, M. K. Gutniak, Q. Zhang et al., "Effects of glucagonlike peptide-1 on endothelial function in type 2 diabetes patients with stable coronary artery disease," American Journal of Physiology-Endocrinology and Metabolism, vol. 287, no. 6, pp. E1209-E1215, 2004.

[86] A. Ceriello, K. Esposito, R. Testa, A. R. Bonfigli, M. Marra, and D. Giugliano, "The possible protective role of glucagon-like peptidel on endothelium during the meal and evidence for an 'endothelial resistance' to glucagon-like peptide 1 in diabetes," Diabetes Care, vol. 34, no. 3, pp. 697-702, 2011.

[87] Ö. Erdogdu, D. Nathanson, Å. Sjöholm, T. Nyström, and Q. Zhang, "Exendin-4 stimulates proliferation of human coronary artery endothelial cells through eNOS-, PKA- and PI3K/Aktdependent pathways and requires GLP-1 receptor," Molecular and Cellular Endocrinology, vol. 325, no. 1-2, pp. 26-35, 2010.

[88] X.-Y. Xie, Z.-H. Mo, K. Chen, H.-H. He, and Y.-H. Xie, "Glucagon-like peptide-1 improves proliferation and differentiation of endothelial progenitor cells via upregulating VEGF generation," Medical Science Monitor, vol. 17, no. 2, pp. BR35BR41, 2011.
[89] C.-Y. Huang, C.-M. Shih, N.-W. Tsao et al., "Dipeptidyl peptidase- 4 inhibitor improves neovascularization by increasing circulating endothelial progenitor cells," British Journal of Pharmacology, vol. 167, no. 7, pp. 1506-1519, 2012.

[90] K. Ban, M. H. Noyan-Ashraf, J. Hoefer, S.-S. Bolz, D. J. Drucker, and M. Husain, "Cardioprotective and vasodilatory actions of glucagon-like peptide 1 receptor are mediated through both glucagon-like peptide 1 receptor-dependent and -independent pathways," Circulation, vol. 117, no. 18, pp. 2340-2350, 2008.

[91] Y. Hattori, T. Jojima, A. Tomizawa et al., "A glucagon-like peptide-1 (GLP-1) analogue, liraglutide, upregulates nitric oxide production and exerts anti-inflammatory action in endothelial cells," Diabetologia, vol. 53, no. 10, pp. 2256-2263, 2010.

[92] B. Hocher, C. Reichetzeder, and M. L. Alter, "Renal and cardiac effects of DPP-4 inhibitors-from preclinical development to clinical research," Kidney and Blood Pressure Research, vol. 36, no. 1, pp. 65-84, 2012.

[93] B. Huisamen, A. Genis, E. Marais, and A. Lochner, "Pretreatment with a DPP-4 inhibitor is infarct sparing in hearts from obese, pre-diabetic rats," Cardiovascular Drugs and Ther$a p y$, vol. 25, no. 1, pp. 13-20, 2011.

[94] M. H. Noyan-Ashraf, M. Abdul Momen, K. Ban et al., "GLP$1 \mathrm{R}$ agonist liraglutide activates cytoprotective pathways and improves outcomes after experimental myocardial infarction in mice," Diabetes, vol. 58, no. 4, pp. 975-983, 2009.

[95] G. Chang, D. Zhang, J. Liu et al., "Exenatide protects against hypoxia/reoxygenation-induced apoptosis by improving mitochondrial function in $\mathrm{H} 9 \mathrm{c} 2$ cells," Experimental Biology and Medicine, vol. 239, no. 4, pp. 414-422, 2014.

[96] S. Ravassa, A. Zudaire, R. D. Carr, and J. Díez, "Antiapoptotic effects of GLP-1 in murine HL-1 cardiomyocytes," The American Journal of Physiology-Heart and Circulatory Physiology, vol. 300, no. 4, pp. H1361-H1372, 2011.

[97] T. Zhao, P. Parikh, S. Bhashyam et al., "Direct effects of glucagon-like peptide-1 on myocardial contractility and glucose uptake in normal and postischemic isolated rat hearts," Journal of Pharmacology and Experimental Therapeutics, vol. 317, no. 3, pp. 1106-1113, 2006.

[98] L. A. Nikolaidis, D. Elahi, T. Hentosz et al., "Recombinant glucagon-like peptide-1 increases myocardial glucose uptake and improves left ventricular performance in conscious dogs with pacing-induced dilated cardiomyopathy," Circulation, vol. 110, no. 8, pp. 955-961, 2004.

[99] S. Bhashyam, A. V. Fields, B. Patterson et al., "Glucagon-like peptide-1 increases myocardial glucose uptake via p38alpha MAP kinase-mediated, nitric oxide-dependent mechanisms in conscious dogs with dilated cardiomyopathy," Circulation: Heart Failure, vol. 3, no. 4, pp. 512-521, 2010.

[100] M. G. Vila Petroff, J. M. Egan, X. Wang, and S. J. Sollott, "Glucagon-like peptide-1 increases cAMP but fails to augment contraction in adult rat cardiac myocytes," Circulation Research, vol. 89, no. 5, pp. 445-452, 2001.

[101] C. M. B. Edwards, J. F. Todd, M. A. Ghatei, and S. R. Bloom, "Subcutaneous glucagon-like peptide-1 (7-36) amide is insulinotropic and can cause hypoglycaemia in fasted healthy subjects," Clinical Science, vol. 95, no. 6, pp. 719-724, 1998.

[102] J. M. Barragan, R. E. Rodriguez, and E. Blazquez, "Changes in arterial blood pressure and heart rate induced by glucagon-like peptide-1-(7-36) amide in rats," American Journal of Physiology, vol. 266, no. 3, pp. E459-E466, 1994. 
[103] J. M. Barragán, R. E. Rodríguez, J. Eng, and E. Blázquez, "Interactions of exendin-(9-39) with the effects of glucagonlike peptide-1-(7-36) amide and of exendin-4 on arterial blood pressure and heart rate in rats," Regulatory Peptides, vol. 67, no. 1, pp. 63-68, 1996.

[104] K. Hirata, S. Kume, S.-I. Araki et al., "Exendin-4 has an antihypertensive effect in salt-sensitive mice model," Biochemical and Biophysical Research Communications, vol. 380, no. 1, pp. 44-49, 2009.

[105] E. S. Horton, C. Silberman, K. L. Davis, and R. Berria, "Weight loss, glycemic control, and changes in cardiovascular biomarkers in patients with type 2 diabetes receiving incretin therapies or insulin in a large cohort database," Diabetes Care, vol. 33, no. 8, pp. 1759-1765, 2010.

[106] L. Blonde, E. J. Klein, J. Han et al., "Interim analysis of the effects of exenatide treatment on $\mathrm{AlC}$, weight and cardiovascular risk factors over 82 weeks in 314 overweight patients with type 2 diabetes," Diabetes, Obesity and Metabolism, vol. 8, no. 4, pp. 436-447, 2006.

[107] J. B. Buse, D. J. Drucker, K. L. Taylor et al., "DURATION-1: exenatide once weekly produces sustained glycemic control and weight loss over 52 weeks," Diabetes Care, vol. 33, no. 6, pp. 12551261, 2010.

[108] H. Goto, T. Nomiyama, T. Mita et al., "Exendin-4, a glucagonlike peptide-1 receptor agonist, reduces intimal thickening after vascular injury," Biochemical and Biophysical Research Communications, vol. 405, no. 1, pp. 79-84, 2011.

[109] M. Nagashima, T. Watanabe, M. Terasaki et al., "Native incretins prevent the development of atherosclerotic lesions in apolipoprotein e knockout mice," Diabetologia, vol. 54, no. 10, pp. 2649-2659, 2011.

[110] M. Arakawa, T. Mita, K. Azuma et al., "Inhibition of monocyte adhesion to endothelial cells and attenuation of atherosclerotic lesion by a glucagon-like peptide-1 receptor agonist, exendin-4," Diabetes, vol. 59, no. 4, pp. 1030-1037, 2010.

[111] X. Qin, H. Shen, M. Liu et al., "GLP-1 reduces intestinal lymph flow, triglyceride absorption, and apolipoprotein production in rats," American Journal of Physiology-Gastrointestinal and Liver Physiology, vol. 288, no. 5, pp. G943-G949, 2005.

[112] J. Hsieh, C. Longuet, C. L. Baker et al., "The glucagon-like peptide 1 receptor is essential for postprandial lipoprotein synthesis and secretion in hamsters and mice," Diabetologia, vol. 53, no. 3, pp. 552-561, 2010.

[113] J. J. Meier, A. Gethmann, O. Götze et al., “Glucagon-like peptide 1 abolishes the postprandial rise in triglyceride concentrations and lowers levels of non-esterified fatty acids in humans," Diabetologia, vol. 49, no. 3, pp. 452-458, 2006.

[114] L. Juntti-Berggren, J. Pigon, F. Karpe et al., "The antidiabetogenic effect of GLP-1 is maintained during a 7-day treatment period and improves diabetic dyslipoproteinemia in NIDDM patients," Diabetes Care, vol. 19, no. 11, pp. 1200-1206, 1996.

[115] J. Zhong, A. Maiseyeu, and S. Rajagopalan, "Lipoprotein effects of incretin analogs and dipeptidyl peptidase 4 inhibitors," Clinical Lipidology, vol. 10, no. 1, pp. 103-112, 2015.

[116] Z. Shah, C. Pineda, T. Kampfrath et al., "Acute DPP-4 inhibition modulates vascular tone through GLP-1 independent pathways," Vascular Pharmacology, vol. 55, no. 1-3, pp. 2-9, 2011.

[117] G. P. Fadini, E. Boscaro, M. Albiero et al., “The oral dipeptidyl peptidase-4 inhibitor sitagliptin increases circulating endothelial progenitor cells in patients with type 2 diabetes: possible role of stromal-derived factor-1 $\alpha$," Diabetes Care, vol. 33, no. 7, pp. 1607-1609, 2010.

[118] E. Schon, S. Jahn, S. T. Kiessig et al., "The role of dipeptidyl peptidase IV in human T lymphocyte activation. Inhibitors and antibodies against dipeptidyl peptidase IV suppress lymphocyte proliferation and immunoglubolin synthesis in vitro," European Journal of Immunology, vol. 17, no. 12, pp. 1821-1826, 1987.

[119] G. R. Flentke, E. Munoz, B. T. Huber, A. G. Plaut, C. A. Kettner, and W. W. Bachovchin, "Inhibition of dipeptidyl aminopeptidase IV (DP-IV) by Xaa-boroPro dipeptides and use of these inhibitors to examine the role of DP-IV in T-cell function," Proceedings of the National Academy of Sciences of the United States of America, vol. 88, no. 4, pp. 1556-1559, 1991.

[120] D. Reinhold, U. Bank, F. Buhling et al., "Dipeptidyl peptidase IV (CD26) on human lymphocytes. Synthetic inhibitors of and antibodies against dipeptidyl peptidase IV suppress the proliferation of pokeweed mitogen-stimulated peripheral blood mononuclear cells, and IL-2 and IL-6 production," Immunobiology, vol. 188, no. 4-5, pp. 403-414, 1993.

[121] D. Reinhold, U. Bank, F. Bühling et al., "Inhibitors of dipeptidyl peptidase IV (DP IV, CD26) induces secretion of transforming growth factor- $\beta 1$ (TGF- $\beta 1$ ) in stimulated mouse splenocytes and thymocytes," Immunology Letters, vol. 58, no. 1, pp. 29-35, 1997.

[122] D. Reinhold, U. Bank, F. Bühling et al., "Inhibitors of dipeptidyl peptidase IV induce secretion of transforming growth factor$\beta 1$ in PWM-stimulated PBMC and T cells," Immunology, vol. 91, no. 3, pp. 354-360, 1997.

[123] T. Tanaka, J. Kameoka, A. Yaron, S. F. Schlossman, and C. Morimoto, "The costimulatory activity of the CD26 antigen requires dipeptidyl peptidase IV enzymatic activity," Proceedings of the National Academy of Sciences of the United States of America, vol. 90, no. 10, pp. 4586-4590, 1993.

[124] T. Tanaka, J. S. Duke-Cohan, J. Kameoka et al., "Enhancement of antigen-induced T-cell proliferation by soluble CD26/ dipeptidyl peptidase IV," Proceedings of the National Academy of Sciences of the United States of America, vol. 91, no. 8, pp. 30823086, 1994.

[125] H. E. Broxmeyer, J. Hoggatt, H. A. O’leary et al., "Dipeptidylpeptidase 4 negatively regulates colony-stimulating factor activity and stress hematopoiesis," Nature Medicine, vol. 18, no. 12, pp. 1786-1796, 2012.

[126] M. Abe, F. Abe, C. Nishimura et al., "Sulphostin, a novel inhibitor of dipeptidyl peptidases IV (DPPIV) that stimulates hematopoiesis in mice," Journal of Antibiotics, vol. 58, no. 2, pp. 111-117, 2005.

[127] L. A. Bristol, W. Bachovchin, and L. Takacs, "Inhibition of CD26 enzyme activity with Pro-boropro stimulates rat granulocyte/macrophage colony formation and thymocyte proliferation in vitro," Blood, vol. 85, no. 12, pp. 3602-3609, 1995.

[128] J. Matsubara, S. Sugiyama, K. Sugamura et al., "A dipeptidyl peptidase- 4 inhibitor, des-fluoro-sitagliptin, improves endothelial function and reduces atherosclerotic lesion formation in apolipoprotein edeficient mice," Journal of the American College of Cardiology, vol. 59, no. 3, pp. 265-276, 2012.

[129] A. R. Aroor, J. R. Sowers, S. B. Bender et al., "Dipeptidylpeptidase inhibition is associated with improvement in blood pressure and diastolic function in insulin-resistant male zucker obese rats," Endocrinology, vol. 154, no. 7, pp. 2501-2513, 2013.

[130] R. P. Mason, R. F. Jacob, R. Kubant, A. Ciszewski, J. J. Corbalan, and T. Malinski, "Dipeptidyl peptidase-4 inhibition with 
saxagliptin enhanced nitric oxide release and reduced blood pressure and sICAM-1 levels in hypertensive rats," Journal of Cardiovascular Pharmacology, vol. 60, no. 5, pp. 467-473, 2012.

[131] P. C. M. Van Poppel, M. G. Netea, P. Smits, and C. J. Tack, "Vildagliptin improves endothelium-dependent vasodilatation in type 2 diabetes," Diabetes Care, vol. 34, no. 9, pp. 2072-2077, 2011.

[132] M. Ayaori, N. Iwakami, H. Uto-Kondo et al., "Dipeptidyl peptidase- 4 inhibitors attenuate endothelial function as evaluated by flow-mediated vasodilatation in type 2 diabetic patients," Journal of the American Heart Association, vol. 2, no. 1, Article ID e003277, 2013.

[133] K. Nakamura, H. Oe, H. Kihara et al., "DPP-4 inhibitor and alpha-glucosidase inhibitor equally improve endothelial function in patients with type 2 diabetes: EDGE study," Cardiovascular Diabetology, vol. 13, no. 1, article 110, 2014.

[134] Z. Shah, T. Kampfrath, J. A. Deiuliis et al., "Long-term dipeptidyl-peptidase 4 inhibition reduces atherosclerosis and inflammation via effects on monocyte recruitment and chemotaxis," Circulation, vol. 124, no. 21, pp. 2338-2349, 2011.

[135] M. Monami, B. Ahrén, I. Dicembrini, and E. Mannucci, "Dipeptidyl peptidase- 4 inhibitors and cardiovascular risk: ametaanalysis of randomized clinical trials," Diabetes, Obesity and Metabolism, vol. 15, no. 2, pp. 112-120, 2013.

[136] S. Wu, I. Hopper, M. Skiba, and H. Krum, "Dipeptidyl peptidase-4 inhibitors and cardiovascular outcomes: metaanalysis of randomized clinical trials with 55,141 participants," Cardiovascular Therapeutics, vol. 32, no. 4, pp. 147-158, 2014.

[137] M. Monami, I. Dicembrini, and E. Mannucci, "Dipeptidyl peptidase- 4 inhibitors and heart failure: a meta-analysis of randomized clinical trials," Nutrition, Metabolism and Cardiovascular Diseases, vol. 24, pp. 689-697, 2014.

[138] N. Gomez, V. Matheeussen, C. Damoiseaux et al., "Effect of heart failure on dipeptidyl peptidase IV activity in plasma of dogs," Journal of Veterinary Internal Medicine, vol. 26, no. 4, pp. 929-934, 2012.

[139] P. A. Read, F. Z. Khan, and D. P. Dutka, "Cardioprotection against ischaemia induced by dobutamine stress using glucagon-like peptide-1 in patients with coronary artery disease," Heart, vol. 98, no. 5, pp. 408-413, 2012.

[140] G. G. Sokos, L. A. Nikolaidis, S. Mankad, D. Elahi, and R. P. Shannon, "Glucagon-like peptide-1 infusion improves left ventricular ejection fraction and functional status in patients with chronic heart failure," Journal of Cardiac Failure, vol. 12, no. 9, pp. 694-699, 2006.

[141] L. A. Nikolaidis, S. Mankad, G. G. Sokos et al., "Effects of glucagon-like peptide-1 in patients with acute myocardial infarction and left ventricular dysfunction after successful reperfusion," Circulation, vol. 109, no. 8, pp. 962-965, 2004.

[142] D. Nathanson, B. Ullman, U. Löfström et al., "Effects of intravenous exenatide in type 2 diabetic patients with congestive heart failure: a double-blind, randomised controlled clinical trial of efficacy and safety," Diabetologia, vol. 55, no. 4, pp. 926935, 2012.

[143] G. G. Sokos, H. Bolukoglu, J. German et al., "Effect of glucagonlike peptide-1 (GLP-1) on glycemic control and left ventricular function in patients undergoing coronary artery bypass grafting," American Journal of Cardiology, vol. 100, no. 5, pp. 824-829, 2007.

[144] E. Standl, "Saxagliptin, alogliptin, and cardiovascular outcomes," The New England Journal of Medicine, vol. 370, no. 5, pp. 483-484, 2014.
[145] N. Iqbal, A. Parker, R. Frederich, M. Donovan, and B. Hirshberg, "Assessment of the cardiovascular safety of saxagliptin in patients with type 2 diabetes mellitus: pooled analysis of 20 clinical trials," Cardiovascular Diabetology, vol. 13, no. 1, article 33, 2014.

[146] D. L. Weir, F. A. McAlister, A. Senthilselvan, J. K. MinhasSandhu, and D. T. Eurich, "Sitagliptin use in patients with diabetes and heart failure: a population-based retrospective cohort study," JACC: Heart Failure, vol. 2, no. 6, pp. 573-582, 2014.

[147] D. L. Bhatt and M. A. Cavender, "Do dipeptidyl peptidase4 inhibitors increase the risk of heart failure?" JACC: Heart Failure, vol. 2, no. 6, pp. 583-585, 2014.

[148] B. M. Scirica, E. Braunwald, I. Raz et al., "Heart failure, saxagliptin and diabetes mellitus: observations from the SAVOR-TIMI 53 randomized trial," Circulation, vol. 130, pp. 1579-1588, 2014.

[149] E. Standl, M. Erbach, and O. Schnell, "Dipeptidyl-peptidase4 inhibitors and heart failure: class effect, substance-specific effect, or chance effect?" Current Treatment Options in Cardiovascular Medicine, vol. 16, article 353, 2014.

[150] S. A. Miller and E. L. St. Onge, "Sitagliptin: a dipeptidyl peptidase IV inhibitor for the treatment of type 2 diabetes," Annals of Pharmacotherapy, vol. 40, no. 7-8, pp. 1336-1343, 2006.

[151] C. F. Deacon and J. J. Holst, "Saxagliptin: a new dipeptidyl peptidase- 4 inhibitor for the treatment of type 2 diabetes," Advances in Therapy, vol. 26, no. 5, pp. 488-499, 2009.

[152] M. Monami, I. Iacomelli, N. Marchionni, and E. Mannucci, "Dipeptydil peptidase- 4 inhibitors in type 2 diabetes: a metaanalysis of randomized clinical trials," Nutrition, Metabolism and Cardiovascular Diseases, vol. 20, no. 4, pp. 224-235, 2010.

[153] T. Stulc and A. Sedo, "Inhibition of multifunctional dipeptidyl peptidase-IV: is there a risk of oncological and immunological adverse effects?" Diabetes Research and Clinical Practice, vol. 88, no. 2, pp. 125-131, 2010.

[154] M. Elashoff, A. V. Matveyenko, B. Gier, R. Elashoff, and P. C. Butler, "Pancreatitis, pancreatic, and thyroid cancer with Glucagon-like peptide-1based therapies," Gastroenterology, vol. 141, no. 1, pp. 150-156, 2011.

[155] R. Vangoitsenhoven, C. Mathieu, and B. van der Schueren, "GLP1 and cancer: friend or foe?" Endocrine-Related Cancer, vol. 19, no. 5, pp. F77-F88, 2012.

[156] R. E. Amori, J. Lau, and A. G. Pittas, "Efficacy and safety of incretin therapy in type 2 diabetes: systematic review and metaanalysis," Journal of the American Medical Association, vol. 298, no. 2, pp. 194-206, 2007.

[157] B. Richter, E. Bandeira-Echtler, K. Bergerhoff, and C. L. Lerch, "Dipeptidyl peptidase-4 (DPP-4) inhibitors for type 2 diabetes mellitus," Cochrane Database of Systematic Reviews, no. 2, Article ID CD006739, 2008.

[158] S. R. Ahmad and J. Swann, "Exenatide and rare adverse events," The New England Journal of Medicine, vol. 358, no. 18, pp. 19701971, 2008.

[159] S. Singh, H.-Y. Chang, T. M. Richards, J. P. Weiner, J. M. Clark, and J. B. Segal, "Glucagonlike peptide 1-based therapies and risk of hospitalization for acute pancreatitis in type 2 diabetes mellitus: a population-based matched case-control study," JAMA Internal Medicine, vol. 173, no. 7, pp. 534-539, 2013.

[160] B. J. Lamont and S. Andrikopoulos, "Hope and fear for new classes of type 2 diabetes drugs: is there preclinical evidence that 
incretin-based therapies alter pancreatic morphology?" Journal of Endocrinology, vol. 221, no. 1, pp. T43-T61, 2014.

[161] M. Monami, I. Dicembrini, and E. Mannucci, "Dipeptidyl peptidase- 4 inhibitors and pancreatitis risk: a meta-analysis of randomized clinical trials," Diabetes, Obesity and Metabolism, vol. 16, no. 1, pp. 48-56, 2014.

[162] R. W. Thomsen, L. Pedersen, N. Møller, J. Kahlert, H. BeckNielsen, and H. T. Sørensen, "incretin-based therapy and risk of acute pancreatitis: a nationwide population-based case-control study," Diabetes Care, 2015. 


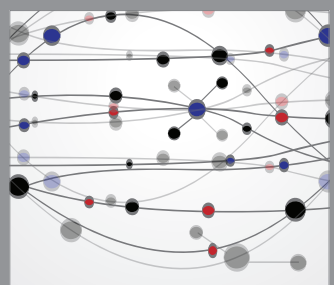

The Scientific World Journal
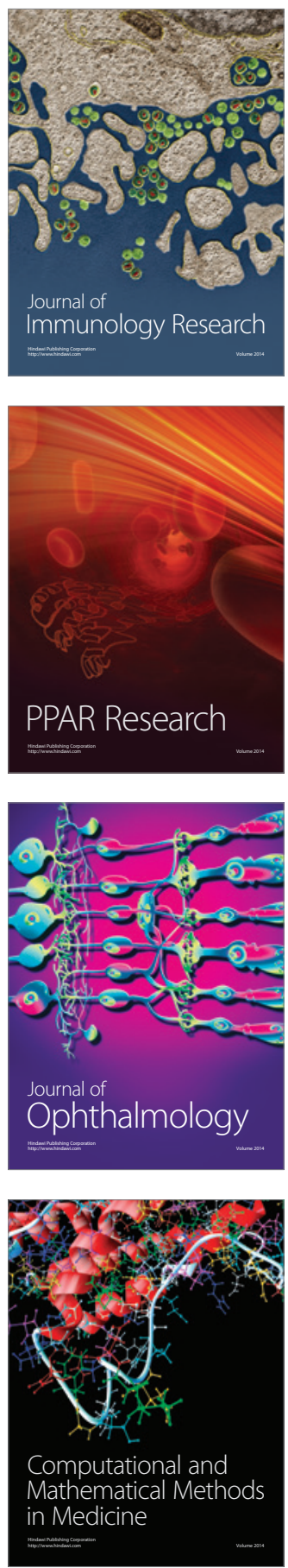

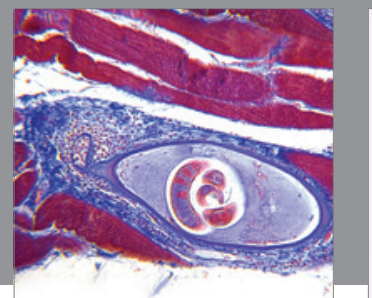

Gastroenterology

Research and Practice
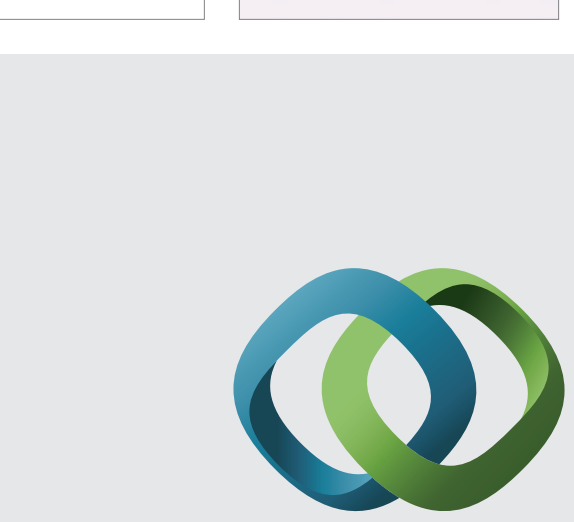

\section{Hindawi}

Submit your manuscripts at

http://www.hindawi.com
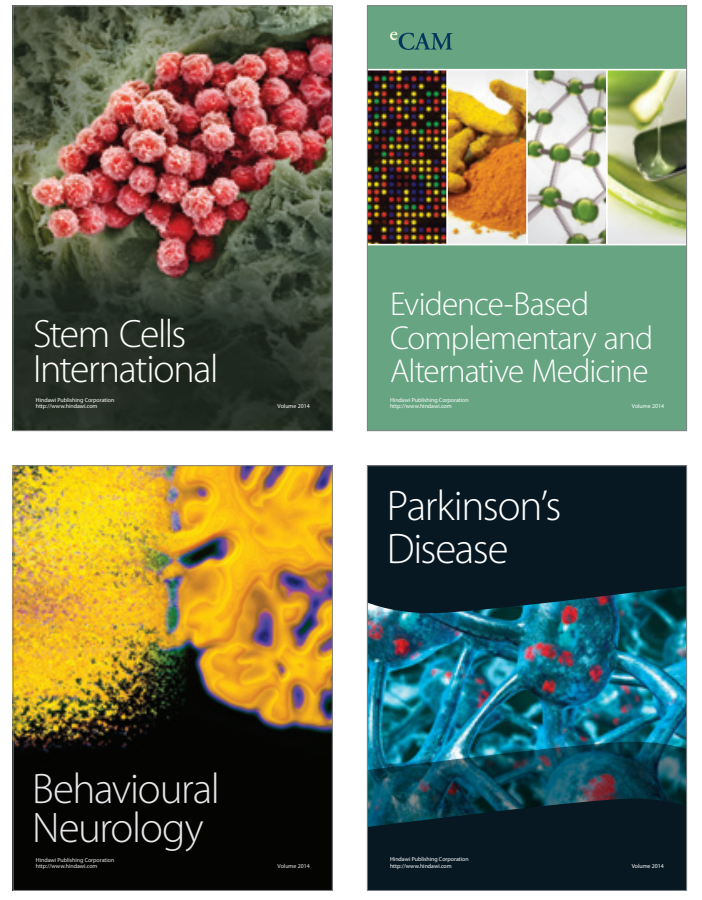
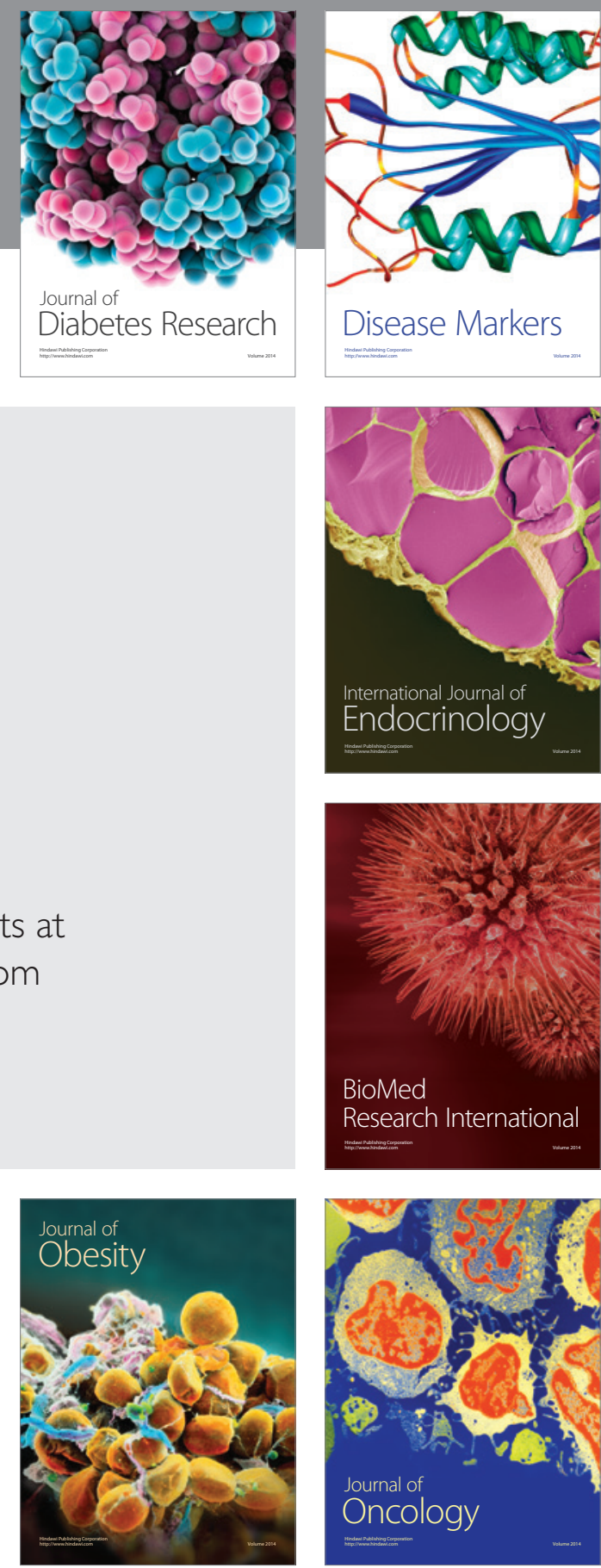

Disease Markers
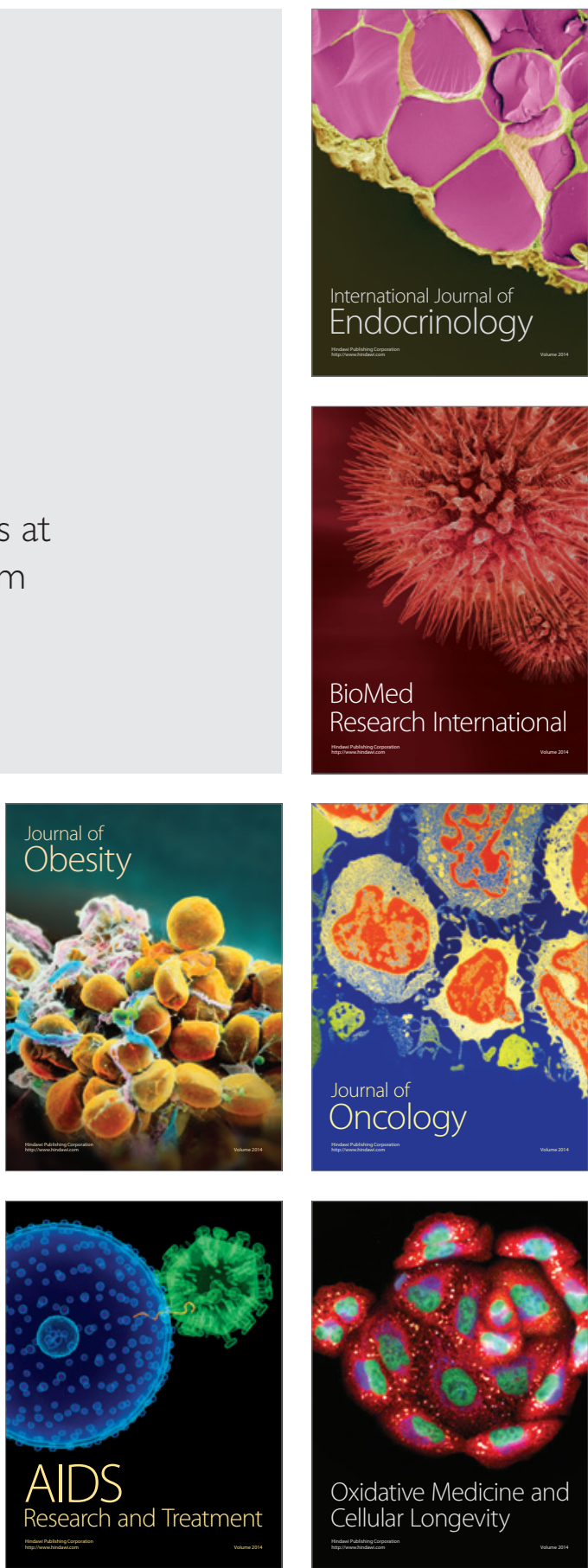